The University of Southern Mississippi

The Aquila Digital Community

Faculty Publications

2005

Monsoon-driven biogeochemical processes in the Arabian Sea

Jerry D. Wiggert

University of Southern Mississippi, jerry.wiggert@usm.edu

Raleigh Hood

University of Maryland Center for Environmental Science, rhood@umces.edu

Karl Banse

University of Washington, banse@u.washington.edu

John Kindle

NRL - Stennis

Follow this and additional works at: https://aquila.usm.edu/fac_pubs

Part of the Atmospheric Sciences Commons, Biogeochemistry Commons, Climate Commons, and the Oceanography Commons

Recommended Citation

Wiggert, J.D., R.R. Hood, K. Banse, and J.C. Kindle, Monsoon-driven biogeochemical processes in the Arabian Sea, Prog. Ocean., v 65, 176-213, 2005.

This Article is brought to you for free and open access by The Aquila Digital Community. It has been accepted for inclusion in Faculty Publications by an authorized administrator of The Aquila Digital Community. For more information, please contact Joshua.Cromwell@usm.edu. 


\title{
Monsoon-driven biogeochemical processes in the Arabian Sea
}

\author{
J.D. Wiggert $^{\mathrm{a}, *}$, R.R. Hood ${ }^{\mathrm{b}}$, K. Banse ${ }^{\mathrm{c}}$, J.C. Kindle ${ }^{\mathrm{d}}$ \\ a ESSIC, University of Maryland, College Park, MD 20742, USA \\ b UMCES, University of Maryland, Cambridge, MD 21613, USA \\ c School of Oceanography, University of Washington, Seattle, WA 98195-7940, USA \\ d Oceanography Division, NRL-Stennis Space Center, MS 39529, USA
}

Available online 29 April 2005

\begin{abstract}
Although it is nominally a tropical locale, the semiannual wind reversals associated with the Monsoon system of the Arabian Sea result annually in two distinct periods of elevated biological activity. While in both cases monsoonal forcing drives surface layer nutrient enrichment that supports increased rates of primary productivity, fundamentally different entrainment mechanisms are operating in summer (Southwest) and winter (Northeast) Monsoons. Moreover, the intervening intermonsoon periods, during which the region relaxes toward oligotrophic conditions more typical of tropical environments, provide a stark contrast to the dynamic biogeochemical activity of the monsoons. The resulting spatial and temporal variability is great and provides a significant challenge for ship-based surveys attempting to characterize the physical and biogeochemical environments of the region. This was especially true for expeditions in the pre-satellite era.

Here, we present an overview of the dynamical response to seasonal monsoonal forcing and the characteristics of the physical environment that fundamentally drive regional biogeochemical variability. We then review past observations of the biological distributions that provided our initial insights into the pelagic system of the Arabian Sea. These evolved through the 1980s as additional methodologies, in particular the first synoptic ocean color distributions gathered by the Coastal Zone Color Scanner, became available. Through analyses of these observations and the first largescale physical-biogeochemical modeling attempts, a pre-JGOFS understanding of the Arabian Sea emerged. During the 1990s, the in situ and remotely sensed observational databases were significantly extended by regional JGOFS activities and the onset of Sea-viewing Wide Field-of-View Sensor ocean color measurements. Analyses of these new data and coupled physical-biogeochemical models have already advanced our understanding and have led to either an amplification or revision of the pre-JGOFS paradigms. Our understanding of this complex and variable ocean region is still evolving. Nonetheless, we have a much better understanding of time-space variability of biogeochemical properties in the Arabian Sea and much deeper insights about the physical and biological factors that drive them, as well as a number of challenging new directions to pursue.
\end{abstract}

(C) 2005 Elsevier Ltd. All rights reserved.

\footnotetext{
* Corresponding author. Present address. CCPO, Old Dominion University, Norfolk, VA 23508-2026, USA. Fax: +1 757683 5550. E-mail address: jwiggert@ccpo.odu.edu (J.D. Wiggert).
} 
Keywords: Arabian sea; Phytoplankton; Ocean color; Monsoon; Biogeochemical modeling; Eddies; Mesoscale processes

\section{Introduction}

Defined solely by its latitudinal position, the Arabian Sea would be considered a tropical oceanic system. However, the region is subject to semiannual wind reversals associated with the Monsoon cycle that result in two periods of elevated biological activity, the Southwest Monsoon (SWM) and Northeast Monsoon (NEM) that occur in boreal summer and winter, respectively. While in both cases monsoonal forcing drives nutrient enrichment of the surface ocean that supports increased rates of primary productivity, different entrainment mechanisms are in force for the SWM and NEM. These highly productive periods are interrupted by the Fall Intermonsoon (FIM) and Spring Intermonsoon (SIM), during which surface winds become relatively quiescent and the Arabian Sea relaxes toward a more typical tropical (i.e., more oligotrophic) character. The extremes in surface forcing conditions make the Arabian Sea a special case for low-latitude seas and an ideal setting for studying the response of an oceanic ecosystem to dynamic meteorological forcing. Over much of the region, this response manifests itself as marked and rapid seasonal changes in phytoplankton distributions so that assessing biological variability and identifying its underlying mechanisms with in situ collections is inherently limited. The advent of satellite-based ocean color measurements [e.g., Coastal Zone Color Scanner (CZCS), Sea-viewing Wide Field-of-View Sensor (SeaWiFS) and Moderate Resolution Imaging Spectroradiometer (MODIS)] has allowed for more complete seasonal separation of the temporal and spatial variability of surface chlorophyll $a$ distributions. They have also proved invaluable in revealing interannual variability that has stimulated fresh insights into the pertinent, underlying physical processes.

Here, we review the evolution of biogeochemical modeling studies of the Arabian Sea, leading up to and including the most recent efforts that have been stimulated by the extensive observations obtained during the JGOFS field campaigns that occurred from 1990 to 1997. Biogeochemical models can provide both a means of testing hypotheses derived from analyzing the observed variability and a means of filling in observational gaps, such as those in the ocean color record caused by cloud cover and aerosol interference during the SWM. The recent combined application of biogeochemical modeling with remote sensing and in situ observations has unveiled a more complete picture of the region's complex biogeochemical variability and underlying dynamics.

In surveying the modeling efforts that have appeared from the early 1990s onwards, we also document our advances in understanding the specific physical processes pertinent to defining the nature of the Arabian Sea's pelagic system. To set the stage for addressing the interdisciplinary modeling studies of the past decade, we provide an overview of the seasonal response of the Arabian Sea circulation to the annual cycle of monsoon forcing. This is supplemented with an overview of observations of the complex mesoscale variability that appears in response to monsoon forcing. These observations have led to important new insights about the contribution of these mesoscale processes to the mean seasonal circulation and biogeochemical variability. With the description of the physical environment as context, we review studies that utilized shipbased measurements of chlorophyll- $a$ to provide the initial perspectives regarding the region's phytoplankton distributions. We then document how these initial assessments of temporal and spatial variability in the region's phytoplankton distributions were reinforced or revised by subsequent in situ observations, including those gathered during the JGOFS efforts of the 1990s, and the burgeoning satellite-based ocean color measurements.

In developing this overview of past biological observations, we focus solely on measurements of chlorophyll- $a$ and forego including HPLC-based or size-fractionated studies of phytoplankton. In short, a 'generic' phytoplankton class is considered as the cornerstone of the pelagic system, which is consistent with the 
treatment in most of the ecosystem formulations utilized by the modeling studies covered herein. We also deliberately avoid discussing observations or model results pertaining to estimates of primary production, as we wish to focus on seasonal and spatial variations in phytoplankton distributions, the mechanisms that lead to these patterns, and the degree to which the modeling efforts to date have been able to simulate the observed variability. However, we suggest that the interested reader consult the overview on Arabian Sea primary productivity by Marra and Barber (2005) that also appears in this special issue. Finally, throughout this review, we do not include studies of the shelf regions; we concentrate on deep coastal waters and the central and northern Arabian Sea, because these areas have received the most comprehensive treatment from both the observational and modeling studies.

\section{Seasonal variability of the Arabian Sea circulation}

\subsection{Atmospheric forcing}

The basin-scale circulation of the Arabian Sea is governed by its response to the monsoon cycle, characterized by upwelling-favorable, south-westerly winds during the SWM reversing to north-easterly (albeit weaker) winds during the NEM. Meteorological measurements from a moored array located at $15.5^{\circ} \mathrm{N}$, $61.5^{\circ} \mathrm{E}$ and deployed from October 1994 to October 1995, have provided the first direct, sub-monthly observations (sampling interval was $7.5 \mathrm{~min}$ ) of the monsoon cycle in the interior of the Arabian Sea (Rudnick et al., 1997; Weller, Baumgartner, Josey, Fischer, \& Kindle, 1998). We refer to this array as the central mooring (Fig. 1, denoted by yellow star). Based on these mooring measurements, the four seasons for the 1994-1995 monsoon year were defined as: June to mid-September for the SWM; mid-September through October for the FIM; November to mid-February for the NEM and mid-February through May for the SIM. The excellent agreement between these observations and results from operational atmospheric prediction models (Weller et al., 1998) suggests that the atmospheric models, for example the US Navy's Operational Global Atmospheric Prediction System (NOGAPS; Fig. 2), may be used to describe the essential characteristics of the spatial and temporal variability of the atmospheric wind forcing throughout the basin. Likewise, Halpern, Freilich, and Weller (1998) found excellent agreement between the observed winds from the mooring and the satellite-derived winds from the ERS-1 scatterometer.

Unfortunately, the excellent agreement between the observed and modelled momentum fluxes did not extend to the buoyancy fluxes (Weller et al., 1998). Hence, the best estimates of buoyancy forcing for the northern Arabian Sea are provided by Weller et al. (2002) for the region and deployment period of the moored array. Their analyses characterized the SWM as having strong winds, moist air, and cloudy skies resulting in a net oceanic heat gain of $89.5 \mathrm{~W} / \mathrm{m}^{2}$. The NEM was characterized by moderate winds, dry air and clear skies resulting in an average loss of heat from the ocean of $19.7 \mathrm{~W} / \mathrm{m}^{2}$. The SIM period experienced light winds, clear skies and strong solar radiation yielding an average heat gain of $101.1 \mathrm{~W} / \mathrm{m}^{2}$, while the FIM period also exhibited light winds with slightly less intense solar radiation, due to somewhat cloudier conditions, that yielded a heat gain of $67.7 \mathrm{~W} / \mathrm{m}^{2}$.

The timing of SWM onset, particularly with respect to the climatological norm, is a topic of considerable interest. Both the atmospheric-model winds (Weller et al., 1998) and the satellite-derived winds (Halpern et al., 1998) reveal significant regional differences in the timing of the onset and relaxation of the winds within a season. For example, the US Navy's operational wind product indicates that the offshore onset of the 1995 SWM was 7-10 days later in comparison to the 1994 and 1996 SWMs, whereas near the Omani coast the timing for all three years was consistent (Weller et al., 1998). Interestingly, 1995 was the occasion of a double onset of the SWM in which the basin-scale winds began to increase and reverse toward the northwest during mid-May only to revert to intermonsoon conditions within a few days. An analysis of this phenomenon by Flatau, Flatau, Phoebus, and Niiler (1997) reported that double onset events occurred in 


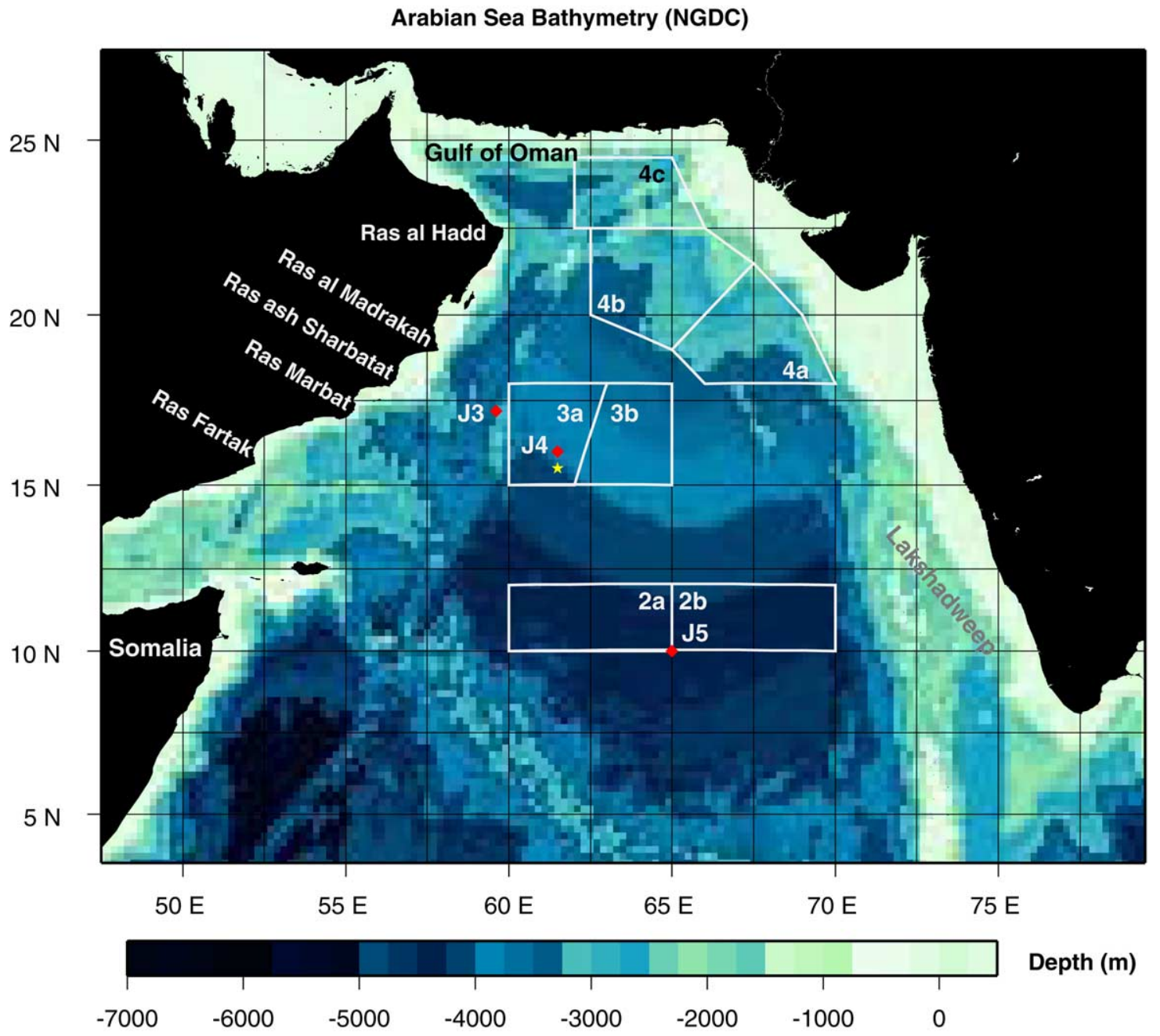

Fig. 1. Arabian Sea Bathymetry obtained from the National Geophysical Data Center (http://www.ngdc.noaa.gov/ngdc.html) illustrating the shelf regions off the Arabian Peninsula, Pakistan and the west coast of India. The three subdivided boxes are as defined in Banse and English (2000), whose labeling convention has been maintained. The yellow star represents the central mooring referred to in the text. The three individually labeled sites (J3, J4 and J5) represent three sediment trap stations of the Arabian Sea Process Study and directly coincide with the stations designated MS3-MS5 in Honjo et al. (1999). The locations of geographic features referred to in the text are also indicated.

only 6 of the 32 years studied (1966-1998). Finally, it should be noted that upwelling-favorable winds along the coast of Oman generally begin in April-May (Weller et al., 1998), prior to the reversal of the winds in the interior of the Arabian Sea. This is consistent with the analysis of ship reports by Fieux and Stommel (1977), which indicates that the onset of upwelling-favorable winds along the Oman coast begins in April. While the winds along the Oman coast in April-May are not as strong as during the SWM period, they appear to be sufficient to generate a coastal upwelling response detected in AVHRR imagery (Kindle, Arnone, \& Smedstad, 2002; Rixen et al., 1996). The potential role of this weak-to-moderate coastal upwelling during April-May in setting the stage for the physical and biogeochemical responses to the primary monsoon onset in June warrants further study. 


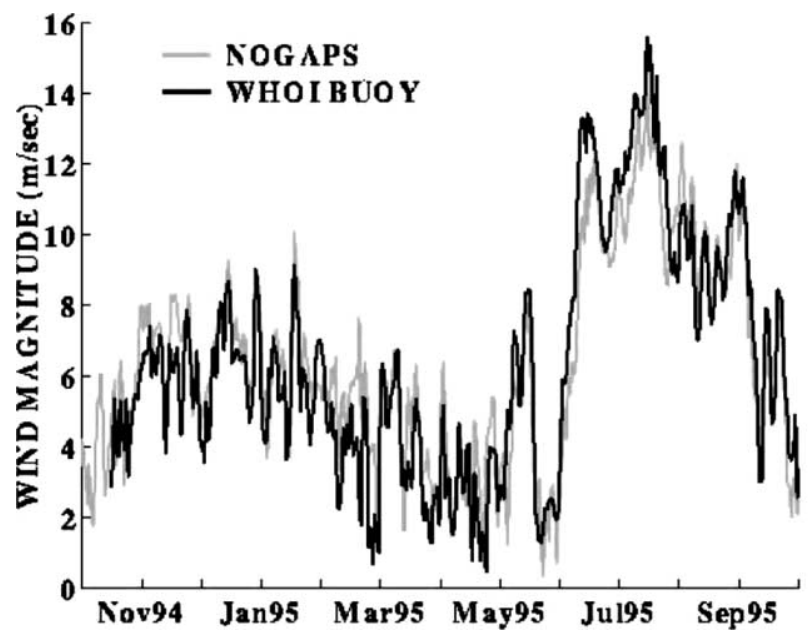

Fig. 2. Time-series of observed wind magnitude (dark line) versus atmospheric-model winds (light line) at $15.5^{\circ} \mathrm{N}, 61.5^{\circ} \mathrm{E}$, for the period October 1994 to October 1995. The atmospheric model winds are from the US Navy's Operational Global Atmospheric Prediction System (NOGAPS; http://meted.ucar.edu/nwp/pcu2/nogaps/).

\subsection{Oceanic responses to the monsoon cycle}

\subsubsection{The Southwest Monsoon}

Historical ship drift records show the existence of the Oman Coastal Current (OCC) north of approximately $14^{\circ} \mathrm{N}$ by early May (Cutler \& Swallow, 1984). In their analysis of the ship drift records, Elliott and Savidge (1990) found a northeastward-flowing OCC during the SWM of around $0.4 \mathrm{~m} \mathrm{~s}^{-1}$ in magnitude and extending to $200 \mathrm{~km}$ offshore. The current turned abruptly to the east off Ras al Hadd, as evidenced by the sharp temperature front in Fig. 3. However, direct measurements of the coastal flow from ADCP instruments during this season in 1987 showed that the northeastward coastal flow

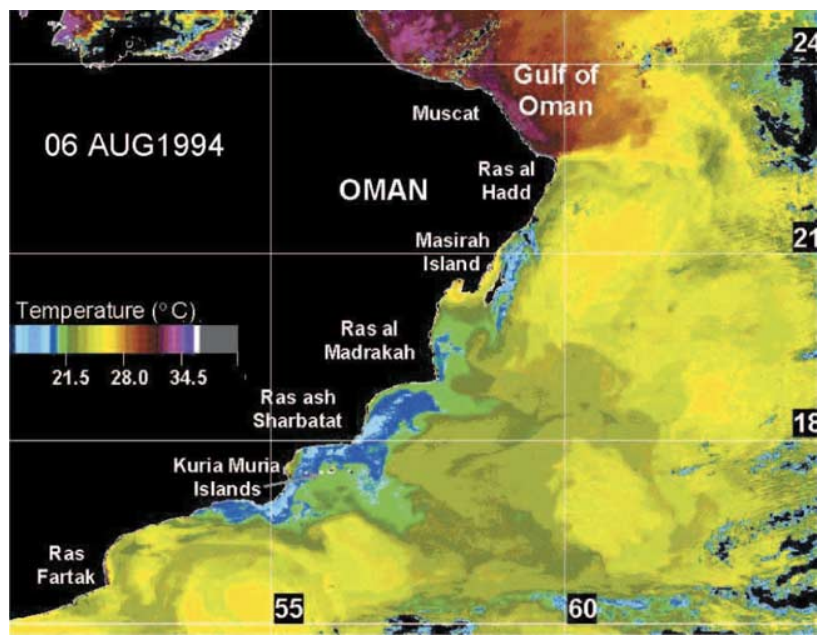

Fig. 3. Advanced very high resolution radiometer (AVHRR) image from 06 August 1994 shows major filaments extending offshore from Ras ash Sharbatat, Ras al Madrakah and Ras al Hadd (image courtesy of R. Arnone). 
weakened toward the southwest from an estimated transport of $\sim 10 \mathrm{~Sv}$ within $100 \mathrm{~km}$ of the coast near Ras al Hadd to weak and variable flow at $\sim 17-18^{\circ} \mathrm{N}$ (Elliott \& Savidge, 1990). Additionally, the ADCP data analyzed by Flagg and Kim (1998) for the 1995 SWM displayed no mean northeastward coastal current, but rather the presence of variable flow characterized by current reversals over relatively small distances. Flagg and Kim (1998) hypothesized that the differences between the direct observations of the OCC and the historical ship drift data may be accounted for by a systematic bias in the ship observations due to the persistent nature of the high winds and sea-state during this period. Clearly, questions remain about the nature of the OCC. During the SWM, is the OCC comprised of several distinct flows of limited alongshore extent or does it consist of a mean manifestation that is intermittently disrupted by pronounced mesoscale variability? Moreover, while we know the fate of the coastal flow after it leaves the coast at Ras al Hadd, we know little of its origin, as the southwestern most extent of the OCC has not been investigated.

When the OCC reaches Ras al Hadd and turns offshore to the northeast and east, it forms the Ras al Hadd Jet. This feature is also referred to as the Ras al Hadd Front (Fig. 3), because it forms the seasonal boundary between the northern Arabian Sea and the Gulf of Oman. As noted above, the observed transport of the OCC prior to turning offshore at Ras al Hadd is $\sim 10 \mathrm{~Sv}$. Flagg and Kim (1998) noted an intensification of the Ras al Hadd Jet in August 1995 following a current reversal along the northeastern Omani coast from northward to southward, thereby supplementing the flow along the Ras al Hadd Front. They speculated that this current reversal was related to the intensification and/or propagation of a cyclonic eddy in the Gulf of Oman. Such a cyclonic eddy may form as part of a double vortex generated by the extension of the Ras al Hadd Jet into open waters (Baker, Arnone, \& Sheres, 1996, also see Section 7.3). Over the course of the 1995 SWM, the estimated transport of the Ras al Hadd Jet varied from 2 to 8 Sv with its maximum occurring in September (Böhm, Morrison, Manghnani, Kim, \& Flagg, 1999).

Among the most prominent SWM features along the Omani coast are filaments and jets (Fig. 3) that are capable of exporting cool, nutrient rich, upwelled coastal waters hundreds of kilometers offshore (Brink et al., 1998; Young \& Kindle, 1994). Elliott and Savidge (1990) described the first direct measurements of these features, which consisted of plumes of cold water extending offshore of the Omani coast in the region between Ras ash Sharbatat and Ras al Madrakah (Fig. 3). This is in approximately the same region as a major filament observed during the 1995 SWM (Brink et al., 1998; Flagg \& Kim, 1998; Lee, Jones, Brink, \& Fischer, 2000; Manghnani, Morrison, Hopkins, \& Böhm, 1998). Such filaments were also present in CZCS imagery of the SWM from 1979 to 1982 (Brock, McClain, Luther, \& Hay, 1991; Brock \& McClain, 1992). Estimates of the offshore transport by individual filaments vary from $\sim 0.4 \mathrm{~Sv}$ (Schott, Dengler, \& Schoenefeldt, 2002) to as large as $\sim 6.0 \mathrm{~Sv}$ (Fischer et al., 2002; Lee et al., 2000). Schott and McCreary (2001) point out that the $2-8 \mathrm{~Sv}$ of net transport by four filaments over the SWM is larger than that expected from offshore Ekman transport, suggesting that the upper end of the filament transport estimate may require recirculation associated with near-coastal eddies.

Some properties of these Arabian Sea filaments have been noted to be similar to filaments appearing off the US Pacific coast (Brink et al., 1998; Elliott \& Savidge, 1990; Fischer et al., 2002). However, Flagg and Kim (1998) view the offshore-directed plumes as part of a major anticyclonic feature that remains essentially in place for approximately six months, thereby extending through the SWM into the winter season. Manghnani et al. (1998) hypothesized that the plume was not part of the offshore deflection of the coastal current, but rather resulted from an interaction between the wind field and anticyclonic mesoscale features that may have existed prior to the onset of the SWM. Results from recent eddy-resolving global models indicate that such eddies are indeed present in the interior of the northern Arabian Sea prior to the onset of the SWM. These eddies intensify during the SWM and propagate westward to interact with coastal circulation features to help produce the pronounced filaments observed (http://www7320.nrlssc.navy.mil/global_nlom/). A complete understanding of the mechanisms that generate these coastal filaments is an outstanding issue. 
The interior of the northern Arabian Sea is dominated by mesoscale eddies, a result first identified by the ADCP analysis of Flagg and Kim (1998). The eddy kinetic energy, which is enhanced in the region within $200 \mathrm{~km}$ of the coast (Flagg \& Kim, 1998), increases in magnitude and areal extent during the SWM but is confined primarily to the region north of $15^{\circ} \mathrm{N}$ (Kim, Flagg, \& Howden, 2001). The characteristic horizontal scale of these eddies varies from $200-500 \mathrm{~km}$ nearshore to $100-200 \mathrm{~km}$ in the interior. Fischer et al. (2002) demonstrated that the pronounced mesoscale eddy field significantly affects the upper ocean heat budget, a finding that is discussed below in more detail. Finally, Kim et al. (2001) established that the primary area of reduced eddy presence in the northern Arabian Sea coincided with the area of the core of the Oxygen Minimum Zone.

In the vicinity of the central mooring during the SW Monsoon of 1995, the mixed layer deepened to about $80 \mathrm{~m}$ and the SST (sea surface temperature) decreased by $\sim 5.5^{\circ} \mathrm{C}$, even though Weller et al. (2002) observed net positive heating of the ocean (see Section 2.1). During the first half of the SWM, the period in which the mixed layer deepened, local wind-driven entrainment was the dominant forcing mechanism in the vicinity of the moored array (Weller et al., 1998, 2002). During the second half of the SWM, horizontal advection associated with the mesoscale eddy field and an evolving coastal filament dominated the upper ocean heat budget as far as $600 \mathrm{~km}$ offshore (Fischer et al., 2002; Weller et al., 2002). These analyses underscore both the episodic nature of these advective events and the degree to which they can modify the seasonal evolution of the surface ocean's thermodynamic structure.

Away from the moored array, Lee et al. (2000) used high-resolution observations from a towed profiler during 1994 and 1995, as well as climatological records of surface forcing and mixed layer depths, to study the seasonal behavior of the surface mixed layer. Their analysis suggests that during the SWM, the shallow mixed layer inshore of the wind maximum results from a balance between wind-driven entrainment and the shoaling tendency of horizontal advection and open-ocean upwelling associated with positive wind stress curl (i.e., Ekman pumping). Offshore of the wind maximum, Lee et al. (2000) show that Ekman pumping and wind-driven entrainment act together to deepen the mixed layer with minimal influence from horizontal advection. They further demonstrate that the so-called $\beta$ term significantly enhances Ekman pumping shoreward of the Findlater Jet and mitigates curl-driven downwelling offshore. The magnitude of the $\beta$ term is set by the meridional gradient of the Coriolis parameter $(f)$ and the zonal wind stress and is generally regarded as negligible. However, in low latitude regions, where persistent, large-magnitude zonal winds are in force, this $\beta$ term contributes significantly to oceanic upwelling associated with Ekman pumping (Lee et al., 2000). The impact of Ekman pumping on the nutrient supply to surface waters inshore and offshore of the wind maximum is discussed in more detail in Sections 4.2, 5.2 and 6.2.

\subsubsection{The Fall Intermonsoon}

Prominent features along the Oman coast generated during the SWM tend to persist into the FIM, as noted above for the cyclonic and anticyclonic eddies associated with the Ras al Hadd Jet. Flagg and Kim (1998) reported the continued presence of the Ras al Hadd Jet, which appeared to maintain its intensity during the intermonsoon period due to the intensification of the southward coastal flow within the Gulf of Oman. Shi, Morrison, Böhm, and Manghnani (2000) reported that cold surface water upwelled during the SWM lingered for nearly a month following the end of the monsoon in bays along the Arabian Sea side of the Omani coast. By the end of the FIM, the characteristically light winds and clear skies lead to a shallow and warm mixed layer in the interior.

\subsubsection{The Northeast Monsoon}

The transition from the FIM to the NEM is heralded by the onset of northeasterly winds in November. In the northern Arabian Sea, the primary circulation response to these winds is the reversal of the OCC, which develops into a persistent southwestward flow. The OCC, which during this season is fed by flow along the northeast coast of Oman, turns the corner at Ras al Hadd and continues southwestward along 
the coast until it is entrained into offshore directed squirts and jets south of $\sim 20^{\circ} \mathrm{N}$ (Flagg \& Kim, 1998). The offshore jets during the NEM season are most likely the result of the interaction between the pronounced eddy field and the coastal circulation. Anticyclonic features that were once directly connected to the coastal circulation during the SWM and FIM periods evolve into separated eddies that exhibit a tendency to propagate southward along the coast and may occasionally directly impact the coastal circulation. Along the northeast coast of Oman, the southward flow decays and reverses to weak northward flow that persists from January to July (Flagg \& Kim, 1998).

The mixed layer behavior during the NEM is characterized by increased deepening with distance offshore and is dominated by convective overturning (Lee et al., 2000). Both are consistent with the results of Weller et al. (1998) in which climatological fields and observations from the central mooring were utilized to demonstrate: (1) the importance of convective overturning to the mixed layer response in the central Arabian Sea during this season, and (2) that the strongest cooling and attendant convective mixed layer deepening occur at mid-basin. The finding that mesoscale eddy signatures during this season are most pronounced in the upper thermocline and are capped by the surface mixed layer demonstrates that the eddy field is less important to mixed layer processes than during the SWM (Fischer et al., 2002). Weller et al. (2002) present a thorough analysis of the mixed layer during the NEM of 1994-1995. They demonstrate that the strong convective forcing not only leads to a surface cooling of $\sim 3{ }^{\circ} \mathrm{C}$ and a deepening of the daily averaged mixed layer to approximately $100 \mathrm{~m}$, but that the mixed layer depth exhibits pronounced diurnal shifts of up to $\sim 85 \mathrm{~m}$ (Fig. 4).

\section{Seasonal and spatial distribution of chlorophyll-a}

\subsection{Distributions observed through the period of the IIOE (1933-1965)}

In addition to being a pioneering example in the realm of international cooperation in oceanographic research and exerting a profound influence on the development of Egyptian oceanography (Aleem \& Morcos, 1984; Deacon \& Rice, 1984), the John Murray Expedition of 1933-1934 provided the first Arabian Sea pigment observations. Gilson (1937) reported pigment content in Harvey's color units from vertically divided net hauls at ten stations that were occupied during the NEM and the subsequent SIM. Six of these

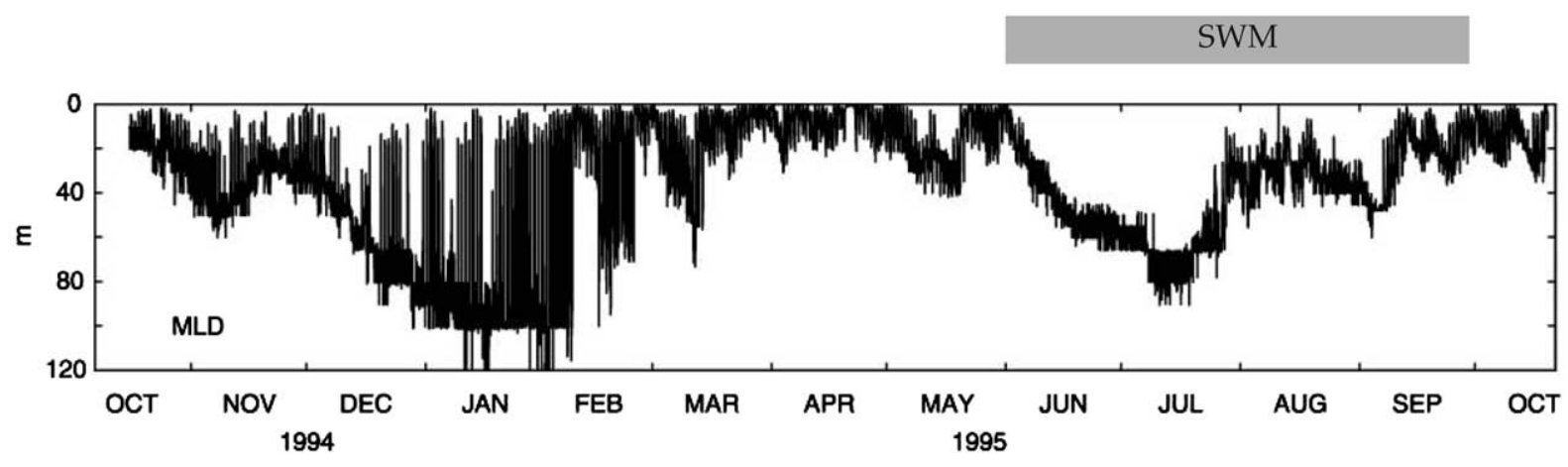

Fig. 4. Time-series of mixed layer depth calculated using the temperature data recorded by thermistors attached to the central mooring. A $0.1^{\circ} \mathrm{C}$ change from the surface temperature was used as the mixed layer criterion. Note that the deepest value for each day (i.e., a maximum value envelope) represents a 'bulk' mixed layer as would be determined using a $1{ }^{\circ} \mathrm{C}$ criterion, and as typically applied when assessing the performance of physical models. The SWM season has been delineated for easy comparison to Figs. 9 and 10 . (Reprinted from Weller et al. (2002), Fig. 3, with permission from Elsevier \#J023.) 
stations were along a section from the Seychelles to the Maldive Islands and beyond, two were in the central Arabian Sea somewhat south of $10^{\circ} \mathrm{N}$, and two were offshore of Somalia. While the nature of the data did not allow comprehensive analysis, Gilson correctly ascertained that sinking particulate organic matter leads to a nutrient-depleted, well-lit upper layer in the permanently stratified tropical ocean, while at depth irradiance is usually too low to allow available nutrients to be utilized fully. Gilson also recognized the importance of coastal upwelling as a means of replenishing surface layer nutrients. Furthermore, the first observations of a secondary nitrite maximum associated with sub-euphotic, low-oxygen environments were made, and the spatial correspondence between such regions and an underlying benthos characterized by elevated hydrogen sulfide concentrations was noted as "suggestive" though a definite causal link was not established (Deacon \& Rice, 1984).

Until the International Indian Ocean Expedition (IIOE) of 1959-1965, the John Murray Expedition remained the most comprehensive set of oceanographic surveys to be conducted in the northern Indian Ocean (Aleem \& Morcos, 1984). During seven cruises in the western Indian Ocean from 1963 to 1964, researchers aboard the RV Anton Brun measured biogeochemical characteristics and performed primary productivity experiments at 231 stations as part of the US Program in Biology of the IIOE (Ryther, Hall, Pease, Bakun, $\&$ Jones, 1966). Sixty of these stations were north of $4^{\circ} \mathrm{N}$. These Arabian Sea data were the basis for several prescient inferences regarding processes affecting biological distribution patterns in the region. Ryther and Menzel (1965) observed the strongly stratified permanent thermocline within the upper $200 \mathrm{~m}$ and the associated nutricline located within or just below the euphotic zone in the central Arabian Sea and conjectured that "Any vertical perturbation... that can break down, disrupt or shift upwards even slightly the barrier of thermal stratification will turn the potential productivity to reality". They also noted the extreme phytoplankton patchiness that typifies the central Arabian Sea during the latter stages of the SWM. Furthermore, due to the extensive upwelling and its northern land boundaries, Ryther et al. (1966) characterized the region as a "nutrient trap", in analogy to the waters off southwest Africa or Peru, that promotes the observed phytoplankton blooms as well as the extensive, subsurface low-oxygen region. Finally, these authors concluded that the elevated phosphate concentrations in the upper $500 \mathrm{~m}$ of the western Arabian Sea contradict the notion that Red Sea waters are upwelled along the Arabian Peninsula during the SWM, as the hydrographic overview of Premchand, Sastry, and Murty (1986) suggests. This conclusion proves to be of particular relevance when conjectures regarding the magnitude of offshore advection were subsequently debated in the literature (Banse, 1987; Brock et al., 1991; McCreary, Kohler, Hood, \& Olson, 1996, Sections 4.2, 5.2 and 6.2).

Krey and Babenerd (1976) summarized in atlas form the pigment data for the entire Indian Ocean from the IIOE (1959-1965, also see Krey, 1973), as well as the few additional observations collected between 1951 and 1971. The authors encountered severe problems due to the absence of a standardized analytic procedure, as well as to uneven temporal and spatial coverage of collections by essentially uncoordinated individual expeditions. Although the shelves were included, the number of stations including the euphotic zone in the Arabian Sea, north of $10^{\circ} \mathrm{N}$ and east of $50^{\circ} \mathrm{E}$, during the two half-years (see time period delineations below) was astonishingly low, 39 and 62, respectively, to which a few surface observations may be added. However, the atlas clearly shows that the chlorophyll content of the open Arabian Sea is appreciably higher than that of the Southern Tropical Indian Ocean at the same latitude.

It is worth noting that Krey and Babenerd (1976) grouped the observations into two halves (NovemberApril and May-October) as their best compromise in recognizing seasons for the entire ocean. For the northern Arabian Sea, however, the dominant November data assigned to the winter "season" happened to represent the strong aftermath of the SWM of 1963 (cf. Ryther \& Menzel, 1965, Figs. 2-4) and would therefore be more appropriately included in the summer "season". In addition, the pigment values of the earlier collections were not lowered to account for the already recognized change of specific chlorophyll absorption coefficients (Banse \& Anderson, 1967); thus, the atlas values for the northern Arabian Sea during the winter "season" are too high. Qasim (1978) plotted the atlas data as annual averages by $5^{\circ}$ squares 
for the entire Indian Ocean. Qasim (1982) combined the same IIOE observations with data obtained during nine Indian cruises in 1973/1974 (INS Darshak) and 1976 (R. V. Gaveshani) and depicted annual averages for $1^{\circ}$ squares north of $15^{\circ} \mathrm{N}$. He concluded that the northernmost Arabian Sea and the area along the coast of the Arabian Peninsula were by far the richest areas of the Indian Ocean in terms of chlorophyll (i.e., phytoplankton biomass).

\subsection{Post-IIOE shipboard observations (1966-1990)}

As noted above, Qasim's 1982 data compilation was based on observations from nine Indian cruises and the IIOE data, with the latter providing the bulk of the non-shelf measurements. This underscores Wooster's observation at the 1983 Mabahiss/John Murray International Symposium that, two decades later, the state of scientific knowledge of the northwest Indian Ocean was still largely based on measurements made during the IIOE (Wooster, 1984). While this is a fitting and well-deserved tribute to the achievements of the IIOE, it also stands as a testament to the lack of attention afforded to the Arabian Sea over the years, despite the dynamic biogeochemical variability it exhibits. It should also be noted that coordinated oceanic research efforts in the Arabian Sea have been (and still are) hampered by the prevailing geopolitical climate.

Russian activity in the Arabian Sea through the early 1990s was considerable, with 294 cruises that collected physical and biological data being performed by YugNIRO (Yakovlev, Trotsenko, \& Kukharev, 1994). In synthesizing results from five other cruises in the northern Arabian Sea (i.e., Box 4 in Fig. 1), Kuzmenko (1994) noted elevated biomass and rates of primary production during the NEM that exceeded values observed during the early SWM, though she acknowledges that data during the latter season are less complete due to the sampling difficulties associated with the high wind conditions. In a major international undertaking, which was in part designed to preserve the historical hydrographic and biological data such as those from the Russian cruises just noted, the National Ocean Data Center (NODC, http://www.nodc.noaa.gov/index.html) has developed a unified database for the world's oceans with standardized data quality methods. This effort resulted in another set of maps of in situ chlorophyll- $a$ in the Arabian Sea (Conkright et al., 1998), averaged by $1^{\circ}$ squares for the entire Indian Ocean and depicted as annual means at standard depths with surface values segregated into four three-month periods (i.e., JFM, AMJ, JAS, OND). The atlases of both Krey and Babenerd (1976) and Conkright et al. (1998) defined seasons arbitrarily such that any given season tends to encompass both monsoonal and intermonsoonal periods. The subsequent NODC compilation showing station locations arranged by years (O'Brien et al., 2002) underscores the deplorable lack of observations in the Arabian Sea in general.

By systematically separating space and time, Banse (1987) developed the first description of the basic features of the seasonal phytoplankton cycle of the open Arabian Sea. He grouped the IIOE pigment data and a few more recent observations into three hydrographic regimes (Fig. 1), similar to those first delineated by Colborn (1975), and plotted the values by month, thereby neglecting possible differences among years (Fig. 5). He pointed out that north of approximately $20^{\circ} \mathrm{N}$ (Box 4 in Fig. 1), two bloom periods occur, one during the SWM, and one during or shortly after the NEM. The latter bloom is caused by the nutrient injection associated with convective mixing that results from the cool, dry atmospheric conditions. These two northern blooms are well separated by a period of low phytoplankton production during the SIM owing to the seasonal heating, which reduces the nutrient supply from below and sets up an oligotrophic regime. Banse (1984) had already drawn a parallel between the processes during the winter in the northern Arabian Sea and the region off Bermuda at about $32^{\circ} \mathrm{N}$. However, for unexplained reasons, a similar semiannual deepening of the mixed layer between about $15^{\circ} \mathrm{N}$ and $18^{\circ} \mathrm{N}$ (Box 3 in Fig. 1) did not result in markedly enhanced chlorophyll during the NEM, though a prominent SWM bloom is apparent. Finally, the more southern waters (Box 2 in Fig. 1) exhibit only a single phytoplankton bloom that occurs toward the end of the SWM. It is consistent with the observed annual cycle in mixed layer depth, which shows only a summertime deepening. 


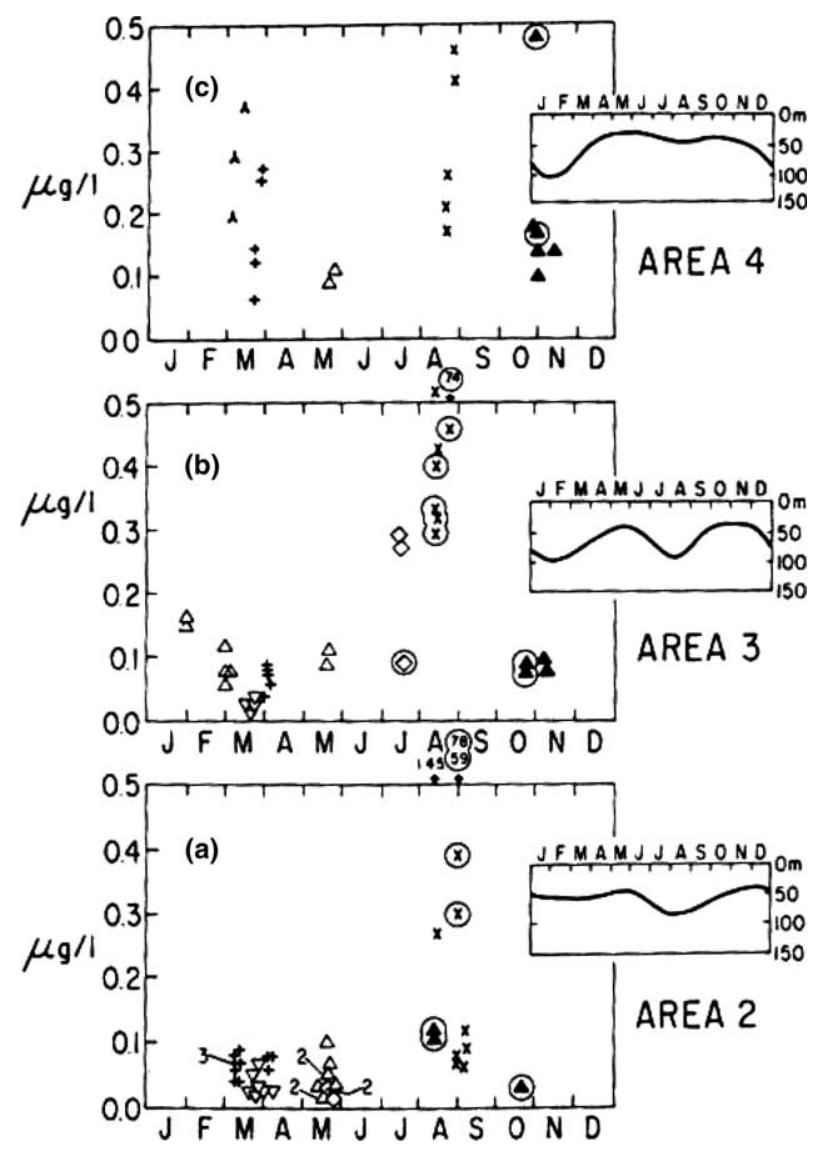

Fig. 5. Seasonal distribution of mean (upper $25 \mathrm{~m}$ ) chlorophyll concentrations. (a) Box 2; (b) Box 3; (c) Box 4.; numbers opposite some stations in (a) designate double or triple observations of the same concentrations. Insets: depth of mixed layer from temperature profiles for each area (redrawn from Colborn, 1975). (Reprinted from Banse (1987), Fig. 2, with permission from Elsevier \#8821.)

\subsection{Satellite-based observations of surface phytoplankton distributions}

The temporally dense coverage of the entire sea by satellites measuring ocean color allows for the development of seasonal characterizations of surface chlorophyll distributions. Fig. 6 shows a set of monthly mean chlorophyll distributions, averaged over the first five years of the SeaWiFS (Sea-viewing Wide Field of view Sensor) mission. These depict the 'climatological' condition over the SeaWiFS observational period for the four monsoon/intermonsoon periods. For non-coastal areas, these images generally reveal highly oligotrophic waters in the southeast and highly productive waters to the north and west, with a seasonal expansion and contraction of these two regimes relative to one another. For instance, during the NEM, surface chlorophyll- $a$ concentrations of $\sim 1 \mathrm{mg} / \mathrm{m}^{3}$ are the norm north of $17.5^{\circ} \mathrm{N}$ and values typically exceed $0.6 \mathrm{mg} / \mathrm{m}^{3}$ north of $12.5^{\circ} \mathrm{N}$ (Fig. 6(a)), whereas during the SIM concentrations south of $20^{\circ} \mathrm{N}$ do not exceed $0.25 \mathrm{mg} / \mathrm{m}^{3}$ (Fig. 6(b)). During the SWM, prominent phytoplankton blooms are apparent, extending oceanward from both the Arabian Peninsula and the southwest coast of India with concentrations exceeding $2.0 \mathrm{mg} / \mathrm{m}^{3}$, (Fig. 6(c)). An extensive offshore bloom between $60^{\circ} \mathrm{E}$ and $65^{\circ} \mathrm{E}$, with concentrations of $1.5-$ $2.5 \mathrm{mg} / \mathrm{m}^{3}$, can also be seen. During the subsequent FIM, the re-establishment of oligotrophic conditions 


\section{SeaWiFS: Arabian Sea Seasonal Climatology}
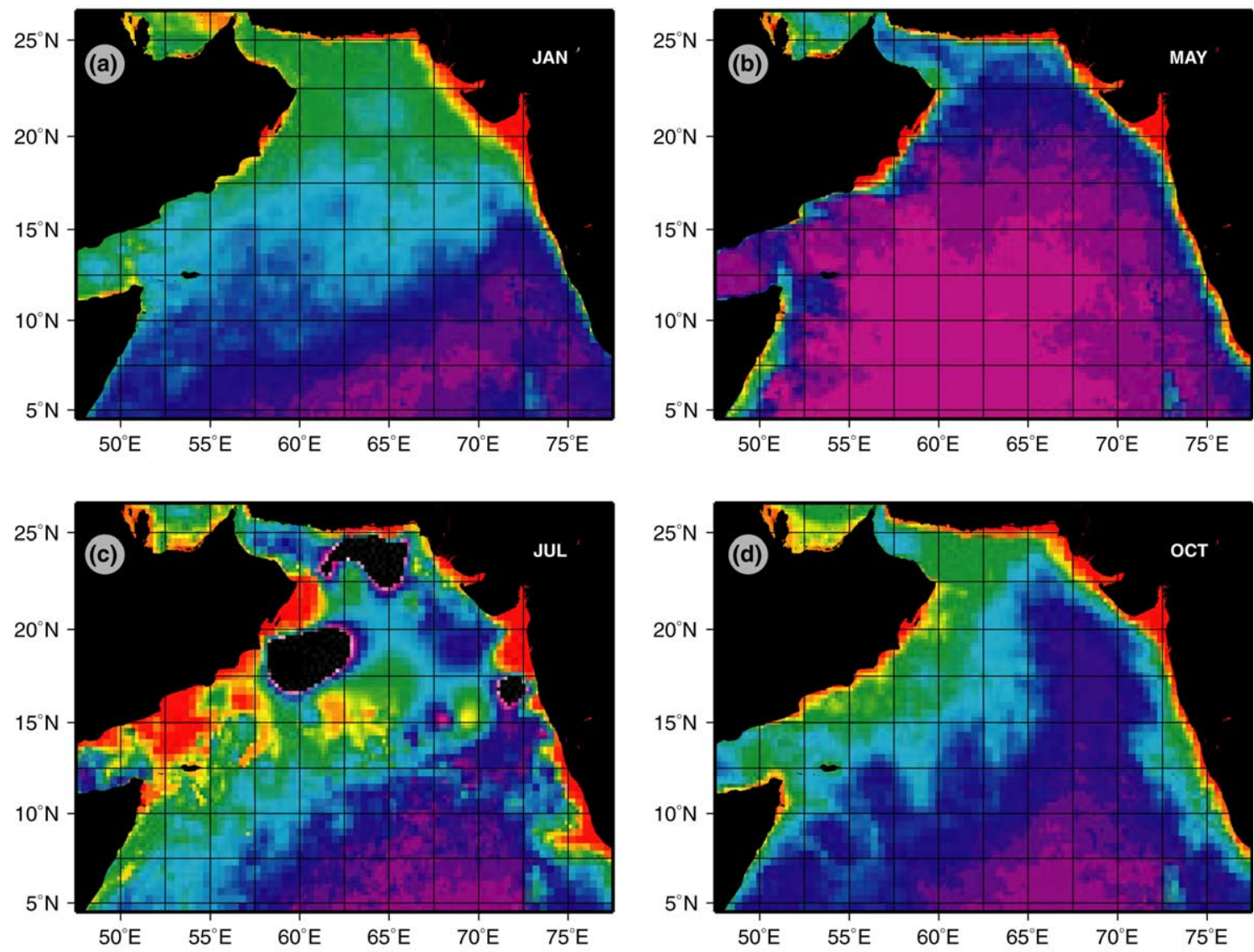

Chla $\left(\mathrm{mg} / \mathrm{m}^{3}\right)$

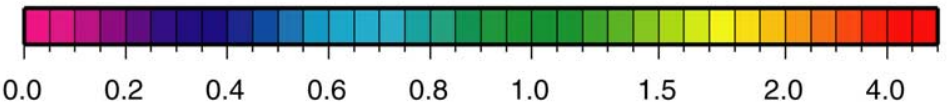

Fig. 6. Seasonal climatology of SeaWiFS chlorophyll a (JAN (a), APR (b), JUL (c), OCT (d)). This climatology was created by averaging the individual composites, for the noted months, over the first five years of the SeaWiFS mission. The color bar has been defined such that no distinction is made for chlorophyll- $a$ concentrations $\geqslant 4.0 \mathrm{mg} / \mathrm{m}^{3}$.

is not as widespread as during the SIM, as west of $65^{\circ} \mathrm{E}$ and north of $15^{\circ} \mathrm{N}$ surface concentrations typically exceed $0.6 \mathrm{mg} / \mathrm{m}^{3}$, and remnants of coastal blooms from the SWM are apparent (Fig. 6(d)).

These satellite-based ocean color observations are also a means of observing interannual variability in surface phytoplankton distributions that previously could only be inferred from meteorological observations (Banse \& English, 2000). The CZCS emphasized the Arabian Sea north of $10^{\circ} \mathrm{N}$ and permitted the full separation of temporal and spatial aspects of the seasonal cycle of pigment except, as noted below, during observationally problematic periods. Fig. 7, from Banse and English (2000), illustrates the principal features first observed by the CZCS, including the decline of pigment levels in the southeastern region in spring after seasonal heating sets in, and the interannual variability. The winter blooms in the north are separate from those that appear toward the end of the SWM (Banse \& English, 1993). Furthermore, the highest 

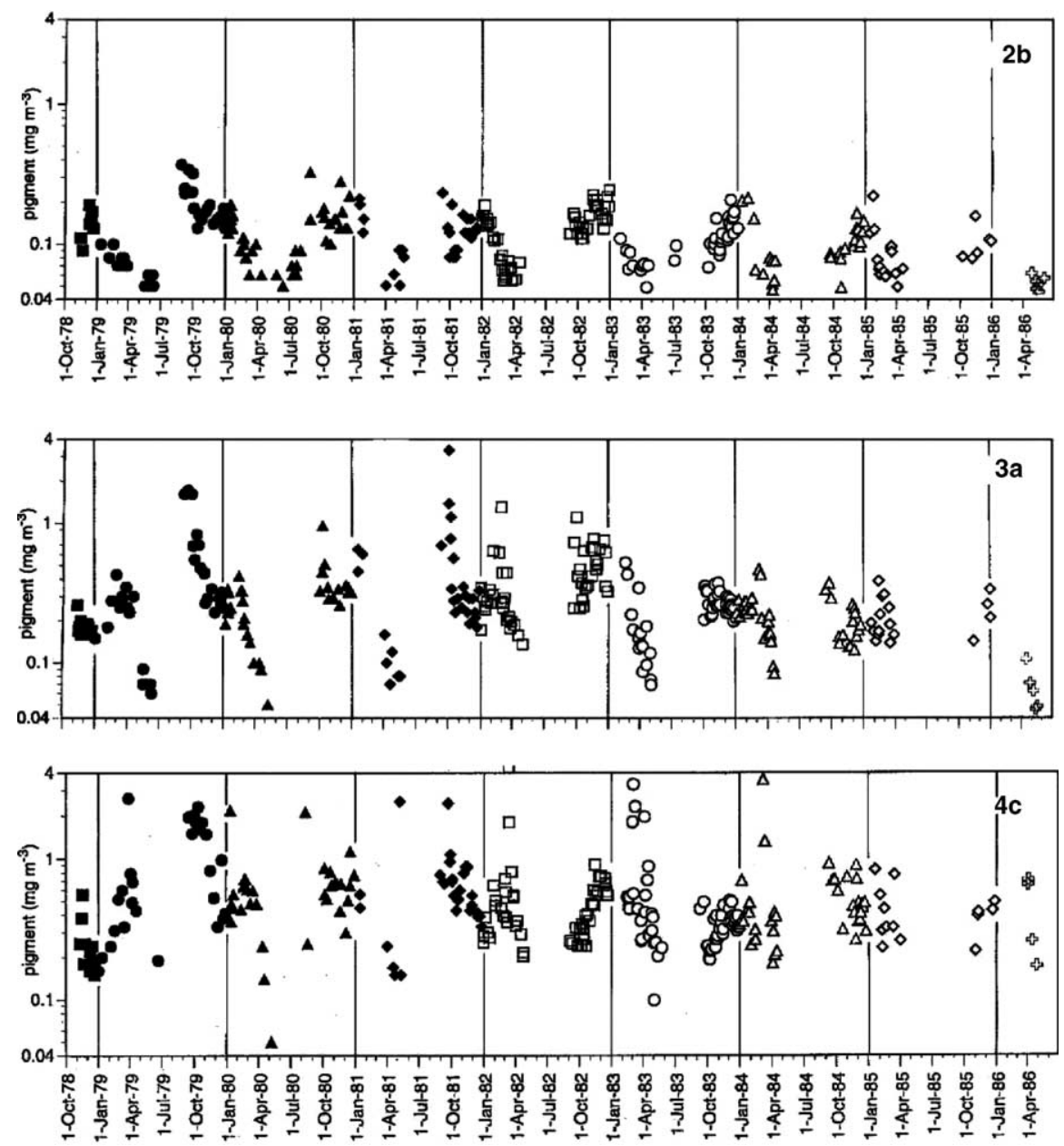

Fig. 7. Medians of chlorophyll concentrations $\left(\mathrm{mg} / \mathrm{m}^{3}\right)$ plotted on logarithmic scale for all CZCS data for boxes, $2 \mathrm{~b}\left(10-12.5^{\circ} \mathrm{N} ; 65-\right.$ $\left.70^{\circ} \mathrm{E}\right), 3 \mathrm{a}\left(15-18^{\circ} \mathrm{N} ; 60^{\circ}\right.$ to approx. $\left.62.5^{\circ} \mathrm{E}\right)$, and $4 \mathrm{c}\left(22.5-24.5^{\circ} \mathrm{N} ; 62\right.$ to approx. $\left.65.5^{\circ} \mathrm{E}\right)$. (Reprinted from Banse and English $(2000)$, Fig. 2, with permission from Elsevier \#8821.)

mean pigment levels in the open sea (more so than the median levels in Fig. 7) were observed at this time, rather than during the SWM (Banse \& English, 2000). Averaged seasonally, pigment increased from south to north. However, even the region between $10^{\circ} \mathrm{N}$ and $12.5^{\circ} \mathrm{N}$ that exhibits the most typical tropical behavior (Box $2 b$ in Fig. 7), exhibited concentrations higher by a factor of two than those of the Southern Tropical Indian Ocean at comparable latitudes.

The winter blooms during 1978/1979 and 1979/1980 were shown in the first evaluation of CZCS observations for the region (Banse \& McClain, 1986), in which large differences in pigment levels between the blooms of 1978/1979 (relatively low) and 1979/1980 were noted but could not be explained by SST or wind data. Estimated pigment levels were later greatly reduced when calculated with better algorithms (Banse \& English, 1993) with the result that during the NEM, higher pigment was found to occur during 1978/1979 than 1979/1980. Thus, interannual variation in the NEM bloom is consistent with the Bermuda paradigm: greater nutrient enrichment of the surface layer resulting from greater wintertime convective mixing leads to 
greater phytoplankton blooms after springtime shoaling of the mixed layer. However, the bloom of the NEM season is less pronounced when deeper convection occurs and is temporally coincident with the entrainment of nutrients into the euphotic zone, rather than lagged as off Bermuda (see further discussion in Sections 5.1 and 6.1).

The seasonal chlorophyll pattern of the Laccadive Sea, south of $16^{\circ} \mathrm{N}$ between the Indian coast and the Laccadive Islands (Lakshadweep) to the west (north of $10^{\circ} \mathrm{N}$ along $\sim 73^{\circ} \mathrm{E}$, see Fig. 1), follows that of the open Arabian Sea to the west, including a decline in chlorophyll concentrations in spring after the establishment of the seasonal thermocline (Lierheimer \& Banse, 2002). In contrast to the area offshore of the Arabian Peninsula, coastal upwelling along western India does not propagate far beyond the shelf break, if at all. Occasional broad zonal outbreaks occur, but most of the newly formed pigment is entrained and advected by the coastal current (Southwest Monsoon Current) to the south of India and Sri Lanka. Incidentally, these outbreaks, the locations of which are quite variable and thus apparently not associated with topographical features, make the Laccadive Sea appear richer than the Arabian Sea to the west in monthly climatologies (Fig. 6(c)). This misleading result is a byproduct of aliasing incurred by temporal averaging.

As the principal results of the evaluation of the in situ and CZCS data, these observations confirm that physical processes determine the timing of the seasonal changes of chlorophyll throughout the open Arabian Sea. Also, interannual variations were noted (Fig. 7) and interpreted within the context of the prevailing meteorological forcing. However, the actual chlorophyll levels maintained over many months for truly large areas cannot be understood from the physics alone - why, for example, are they not one-half or three times those observed, and why do they never approach zero? Without doubt, grazing plays the largest role but it is unclear whether the lowest concentrations are established and maintained by a threshold behavior below which grazers cannot clear the water or whether top-down control of the grazers by their predators determines phytoplankton mortality (Banse, 2002; Calbet \& Landry, 1999; Strom, Miller, \& Frost, 2000).

While these ocean color observations significantly enhance our comprehension of the spatial and temporal variability in phytoplankton distributions, they also have inherent shortcomings. Within the present context, the most conspicuous is that clouds and aerosols impede successful ocean color retrievals, which is especially problematic over the northern Arabian Sea for a good part of the SWM. Indeed, three extensive data gaps are apparent in the July climatological distribution (Fig. 6(c)), indicating that over the first five years of the SeaWiFS mission, no observations in these three areas were deemed usable by the standard data processing algorithms employed by the Distributed Active Archive Center (DAAC) of the Goddard Space Flight Center (GSFC) (http://daac.gsfc.nasa.gov). Furthermore, in the particular case of SeaWiFS's predecessor, CZCS, complete coverage of the Arabian Sea was not possible due to logistical constraints such as power availability and insufficient recording media (C. McClain, pers. commun.). At best, data return over the CZCS operational period (1978-1986) approached 70\% in the relatively cloud-free regions. This value is based on an analysis of CZCS data that has been recently reprocessed to allow for direct comparison with the SeaWiFS observations and the examination of decadal variability (Gregg \& Conkright, 2002). It should be noted that through the combined impact of the above-mentioned observational and logistical constraints, CZCS data return was generally much lower than 70\% (e.g., see Fig. 4 in Brock et al., 1991). The difficulties inherent in analyzing ocean color data from the SWM, and CZCS observations in particular, are well illustrated in the one month composite image of the early SWM (Fig. 8(a)). Despite these limitations, the broad temporal and spatial patterns revealed in these data revolutionized our understanding of the Arabian Sea ecosystem.

Recently, the evolution of the SWM bloom has been described more clearly through the application of a spectral matching algorithm (SMA) that profoundly improves ocean color retrievals during high dust periods (Banzon, Evans, Gordon, \& Chomko, 2004). Through the application of this method, an increase in data return of $\sim 75 \%$ over the northern Arabian Sea was achieved (Banzon, Evans, Gordon, \& Chomko, 2002). In addition, SMA-retrieved chlorophyll- $a$ concentrations appear to be up to $\sim 25 \%$ lower than concentrations determined using earlier standard algorithms (based on data shown in Fig. 4 of Banzon et al., 
CZCS Composites (1979)

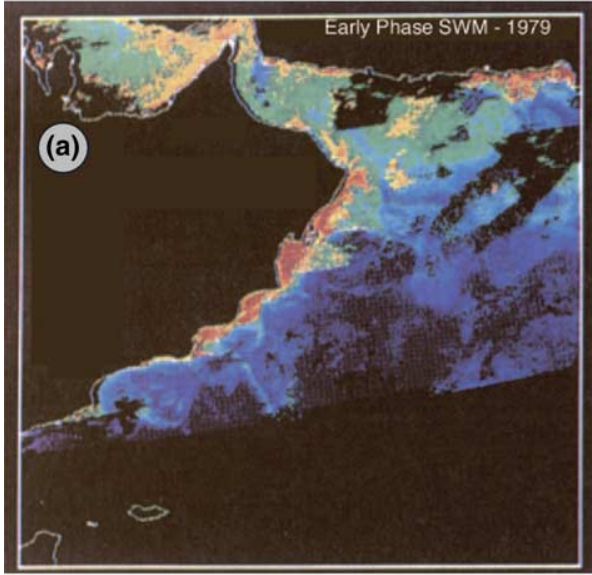

Pigment Concentration $\left(\mathrm{mg} / \mathrm{m}^{3}\right)$

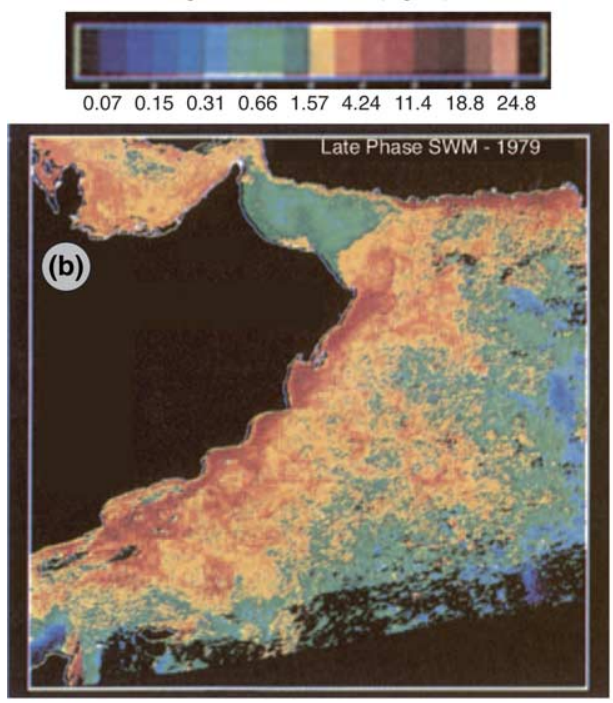

Model: 2-Month Curl-Driven Thermocline Displacement
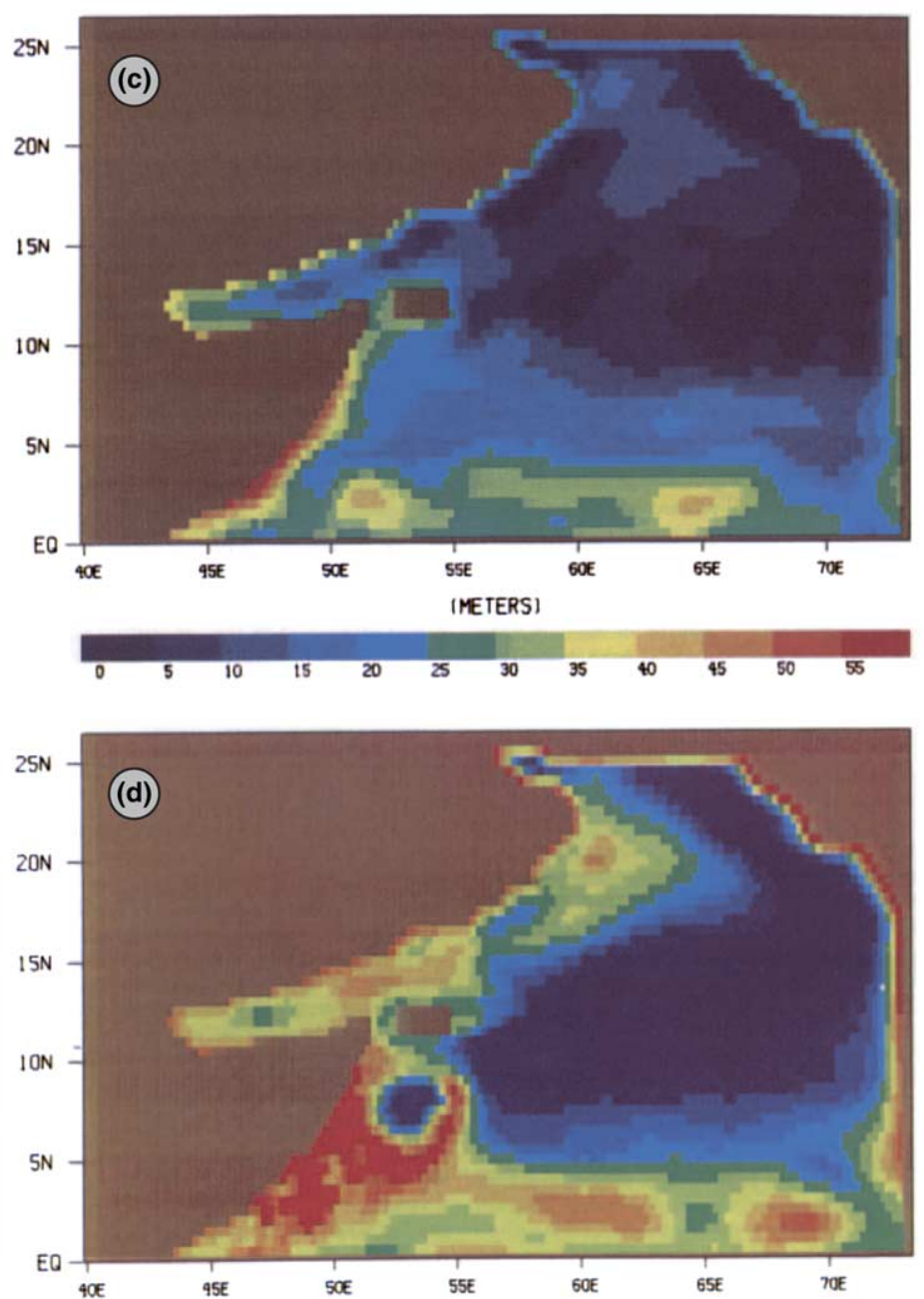

Plates 1, 2 and 8 from Brock et al. 1991

Fig. 8. CZCS pigment concentration composite for the (a) early and (b) late phase of the 1979 SWM and net thermocline displacement for the 2-month period ending on (c) 16 June 1979 and (d) 16 August 1979. (Reprinted from Brock et al. (1991). Copyright 1991 American Geophysical Union. Plates 1, 2 and 8 were reproduced/modified by permission of American Geophysical Union.)

2002). This discovery has significant implications for analyses that use ocean color data to estimate primary production (e.g., Behrenfeld \& Falkowski, 1997) or the impact of phytoplankton on water column heating (Sathyendranath, Gouveia, Shetye, Ravindran, \& Platt, 1991). SMA-derived ocean color data for the 2000 SWM indicate that the season's phytoplankton bloom was a single, prolonged event rather than a series of blooms and that filament structures appeared only in July-August. Banzon et al. (2004) note the temporal coincidence between the appearance of these filaments and the seasonal weakening of the Findlater Jet. One characteristic of such atmospheric weakening is more pronounced across-jet variations in the wind field that may contribute to the generation of these filaments, a mechanism that warrants further study. 


\subsection{The deep chlorophyll maximum}

There are a number of possible mechanisms that can lead to the development of a deep chlorophyll maximum (DCM). These include sinking of an aggregated phytoplankton bloom, subduction of chlorophyll-rich water at the offshore edge of coastal upwelling, and advective transport within filaments or squirts emanating from the coast. Such filament structures have been noted off Oman (see Section 2.2.1) and, in the California Current, have been observed to transport phytoplankton several hundred meters downward (Barth et al., 2002; Hood, Abbott, \& Huyer, 1991). In general however, the DCM is a common, semi-permanent feature that develops in stratified waters as surface phytoplankton concentrations decrease in conjunction with the depletion of surface nutrients and the cessation of upward nutrient fluxes (e.g., Jamart, Winter, Banse, Anderson, \& Lam, 1977). In addition to shutting down the vertical flux of nutrients, stratification confines subsurface phytoplankton populations to permanently reduced irradiance levels. In such a light environment, phytoplankton become shade-adapted, which manifests as an increase in the chlorophyll-to-carbon ratio, though phytoplankton carbon concentration in the DCM is usually enhanced over that of the water above.

The DCM, first reported for the Arabian Sea by Yentsch (1965), is widespread when near-surface development of phytoplankton is absent. The DCM in the central Arabian Sea during the SIM season is a prominent source of export production in an otherwise regenerating pelagic system (Pollehne, Klein, \& Zeitschel, 1993). Export flux during this period consisted primarily of copepod-produced fecal pellets, but a vertical speciation of phytoplankton also occurred, with, picocyanophytes in the near-surface and diatoms and coccolithophores in the DCM. In situ profiles demonstrate that the DCM is most pronounced and spatially extensive during the SIM (e.g., Bhattathiri et al., 1996; Gundersen, Gardner, Richardson, \& Walsh, 1998; Kovaleva, 1970). The fluorometer profile sections of Gundersen et al. (1998) also reveal offshore DCMs during the mid-to-late SWM and early NEM (see their Figs. 8 and 9), which is consistent with the station profiles presented in Barlow, Mantoura, and Cummings (1999). An offshore DCM during the FIM was also apparent in the SeaSoar chlorophyll sections along the southern US JGOFS line (see Fig. 13 in Lee et al., 2000). During the NEM, chlorophyll was uniformly distributed within a deepened mixed layer north of $15^{\circ} \mathrm{N}$ along the southern line (Gundersen et al., 1998; Lee et al., 2000).

\section{The pre-JGOFS biogeochemical modeling efforts}

\subsection{The seasonal relationship between the mixed layer and the euphotic zone}

Several studies have attempted to assess seasonal changes in mixed layer primary productivity by applying a CZCS-derived monthly climatology of surface phytoplankton distribution to monthly climatologies of mixed layer depth and cloudiness (Brock, Sathyendranath, \& Platt, 1993; Brock, Sathyendranath, \& Platt, 1994; Sathyendranath \& Platt, 1994). These investigations interpreted the observed variability in concentrations of phytoplankton biomass as a fundamentally 1D response to the seasonal variation of both mixed layer depth and downwelling irradiance. Sathyendranath and Platt (1994) analyzed the semiannual deepening of the mixed layer and concomitant increase in surface chlorophyll concentration in the central Arabian Sea (see their Fig. 3) and suggested that the canonical Sverdrup spring bloom hypothesis should not be indiscriminately applied to this region. However, the fundamental precepts advanced to explain onset of the vernal bloom (Sverdrup, 1953) are not solely applicable to the mechanisms associated with conditions in the North Atlantic Ocean in springtime. This conclusion has been borne out by the recent analyses of Arabian Sea bloom dynamics described later (see Section 6.1).

The phytoplankton blooms of the monsoons are associated with deepening mixed layers. The physical processes responsible for this deepening are convective mixing and wind stirring during the NEM, and 


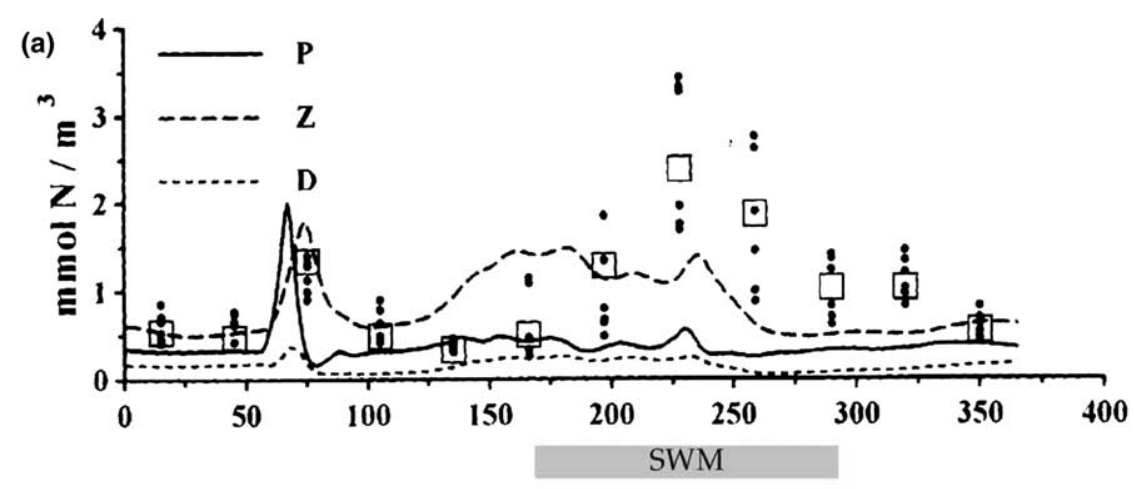

(b) $P_{m}-\cdots--Z_{m}-\cdots-D_{m}$

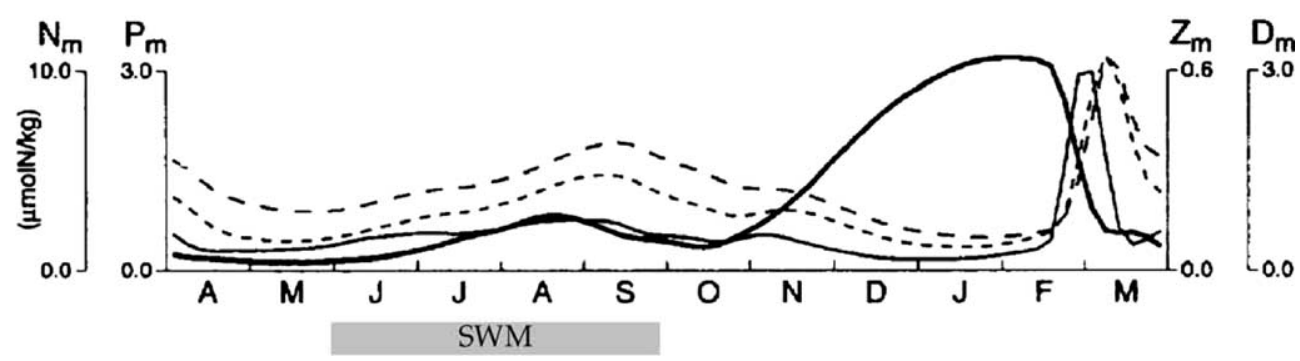

Fig. 9. Comparison of two biogeochemical model solutions from within Box 4. Since three different time lines are presented, the SWM period is delineated for each solution. (a) Time plots of phytoplankton (P), zooplankton (Z) and detritus (D) in the surface mixed layer. The squares denote monthly mean surface chlorophyll concentration as measured by CZCS at the model grid point, while the circles denote the same for the surrounding grid points within $1^{\circ}$ of latitude/longitude. (b) Time plots of inorganic nitrogen $\left(\mathrm{N}_{\mathrm{m}}\right)$, phytoplankton $\left(\mathrm{P}_{\mathrm{m}}\right)$, zooplankton $\left(\mathrm{Z}_{\mathrm{m}}\right)$, detritus $\left(\mathrm{D}_{\mathrm{m}}\right)$. (For $(\mathrm{a})$ : reprinted from Ryabchenko et al. (1998). Copyright 1998 American Geophysical Union. Fig. 1 was reproduced/modified by permission of American Geophysical Union. For (b): reprinted from McCreary et al. (1996), Fig. 4, with permission from Elsevier \#J023.)

coastal upwelling and offshore Ekman pumping during the SWM (Brock et al., 1994). Brock et al. (1993) argued that, due to shifts in hydrographic and trophic states, the intermonsoon periods should be regarded as more than quiescent intervals between the SWM and NEM. Results from their modeling of the in situ light field suggested that during the monsoons, the upper thermocline is extremely light limited, whereas during the intermonsoon periods the euphotic zone extends well into this region of the water column. This increase in euphotic zone depth is a direct consequence of reduced concentrations of chlorophyll- $a$ in the mixed layer within waters characterized by near-oligotrophic conditions, and the resulting upper thermocline photosynthesis leads to the development of a DCM. At the end of the SIM, the bulk of the Arabian Sea exhibits such conditions (Brock et al., 1994). The numerical experiments of Brock et al. (1993) suggested that during the FIM the DCM should be widespread, which has been confirmed by direct observations, as discussed in Section 3.4.

\subsection{What drives the extensive SWM phytoplankton bloom?}

In the early 1990s there was considerable debate about the mechanisms that supply nutrients to support offshore phytoplankton blooms in the central Arabian Sea during the SWM. While it was clear that the Findlater Jet was the governing factor, the exact means by which blooms were supported was an open 
question. The Findlater Jet is directed essentially parallel to the coastline of the Arabian Peninsula and its axis lies roughly $600 \mathrm{~km}$ offshore. Shoreward of this axis, it was clear that a combination of upward Ekman pumping and coastal upwelling combine to supply nutrients to the euphotic zone (Bauer, Hitchcock, \& Olson, 1992; Brock et al., 1991; Smith \& Bottero, 1977; Swallow, 1984). Oceanward of this axis, downward Ekman pumping, which acts to deepen the mixed layer and negatively impacts euphotic zone nutrient availability, was considered the dominant forcing mechanism (Bauer, Hitchcock, \& Olson, 1991; Bauer et al., 1992). Yet the CZCS imagery clearly shows that elevated surface chlorophyll concentrations, exceeding

$1 \mathrm{mg} / \mathrm{m}^{3}$, extend as far as $700-800 \mathrm{~km}$ offshore during the latter part of the SWM (Fig. 8(b)).

Brock et al. (1991) concluded that upward Ekman pumping was the essential mechanism behind the nutrient transport that fuels the extensive offshore phytoplankton blooms, even though their distributions of upward Ekman pumping and two-month integrated thermocline displacements do not extend more than $450 \mathrm{~km}$ offshore (Fig. 8(c) and (d)). They also concluded that offshore advection of nutrient-rich waters upwelled along the Omani coast was not likely to be a major contributor to the offshore blooms, despite observations of low-salinity waters over $800 \mathrm{~km}$ offshore reported by Banse (1987). In a subsequent analysis of interannual variability based on the first four years of CZCS observations for the SWM, Brock and McClain (1992) reported that the Ekman pumping distribution for all four years was remarkably similar, despite notably reduced wind stress in 1982. This weaker SWM coincided with both lower concentrations and less extensive distributions of surface chlorophyll, which should have indicated that Ekman pumping was not the sole mechanism in force.

\section{The state-of-the-art coming into the JGOFS Arabian Sea Process Studies}

\subsection{Large-scale biogeochemical variability}

The first modern, large-scale, coupled biogeochemical modeling studies of the Arabian Sea were carried out by McCreary et al. (1996), and shortly thereafter, by Ryabchenko, Gorchakov, and Fasham (1998). Although the ecosystem models used in these studies are quite different, both were run at relatively low horizontal resolution $\left(0.5^{\circ}\right.$ and $1^{\circ}$, respectively), and they were forced with climatological data. Both models also employed similar mixed layer formulations (based upon Kraus \& Turner, 1967). Probably due to their similar treatment of the physical system, the solutions were quite comparable, revealing pronounced phytoplankton blooms in association with the seasonal monsoon cycle, and distinct spatial variations in the bloom dynamics (Figs. 9 and 10).

Perhaps the most important advance in our understanding that emerged from these studies was the characterization of phytoplankton growth responses in terms of three distinct physical processes: (1) detrainment blooms that are stimulated by increased daily irradiance received by phytoplankton due to mixed layer shoaling that follows the relaxation of monsoon winds in February-March (Figs. 9 and 10(b)), and in September (Fig. 10(a) and (b)); (2) entrainment blooms that are stimulated by the increase in nutrients associated with the deepening of the mixed layer during the onset of the SWM (Fig. 10(a) and (b)); and (3) growth stimulated by nutrients supplied by coastal upwelling as observed along the coasts of Oman and Somalia during the SWM (Figs. 4a, b in McCreary et al., 1996 and Figs. 1b, c in Ryabchenko et al., 1998). The combination of these processes, along with horizontal advection of nutrient-rich water from the coastal zone into the central Arabian Sea, appeared to provide the full suite of physical mechanisms required to explain observed phytoplankton (chlorophyll) variability.

However, in retrospect, it is clear that compared to reality, the bloom dynamics in these models were too simple and in some cases incorrect. Both models predicted relatively low phytoplankton biomass (and presumably production) during the monsoons, followed by strong detrainment blooms after the relaxation of the winds. These effects were particularly pronounced in both the McCreary et al. (1996) and Ryabchenko 

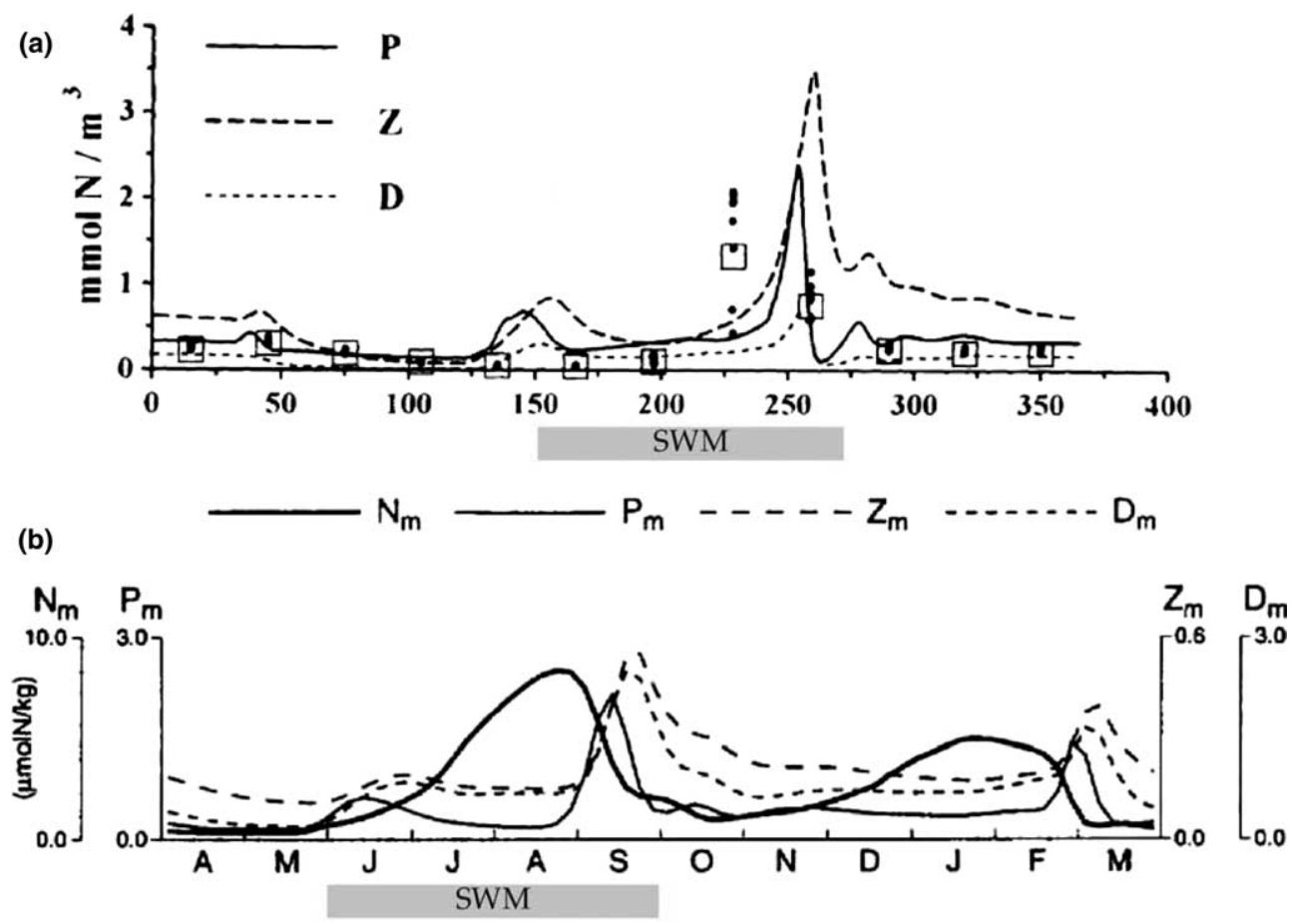

(c)

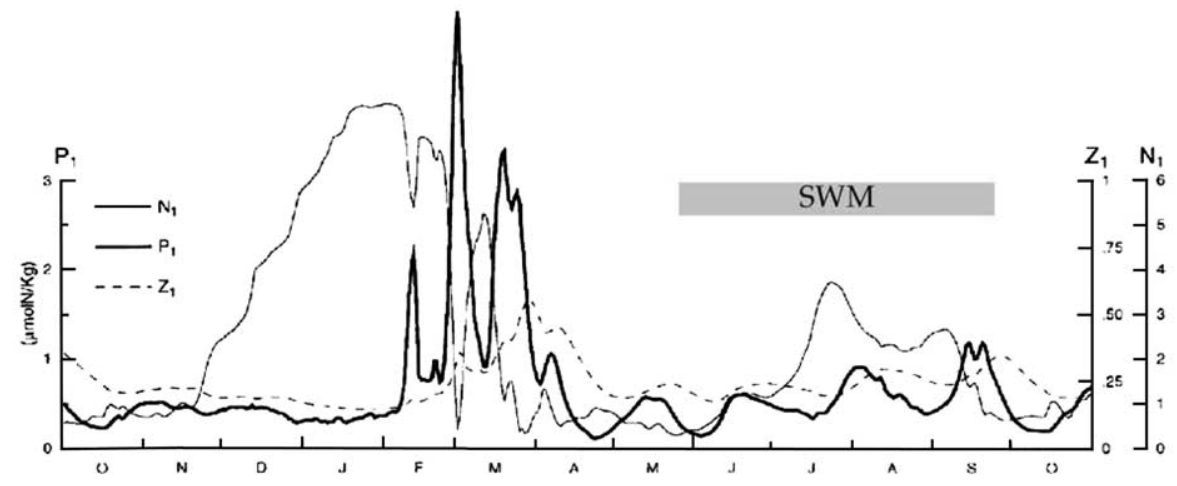

Fig. 10. Comparison of three biogeochemical model solutions from within Box 3. (a) Similar to Fig. 9(a) but for the central basin. (b) Similar to Fig. 9(b) but for the northern basin. (c) Time plots of surface layer inorganic nitrogen $\left(\mathrm{N}_{1}\right)$, phytoplankton $\left(\mathrm{P}_{1}\right)$ and zooplankton $\left(\mathrm{Z}_{1}\right)$. The model configuration differences between this solution and that in (b) consist of the application of daily winds and diurnal forcing, and Io (i.e., the half saturation constant in the light formulation) was decreased from 100 to $40 \mathrm{~W} / \mathrm{m}^{2}$. (For (a): reprinted from Ryabchenko et al. (1998). Copyright 1998 American Geophysical Union. Fig. 1 was reproduced/modified by permission of American Geophysical Union. For (b): reprinted from McCreary et al. (1996), Fig. 4, with permission from Elsevier \#J023. For (c): reprinted from McCreary et al. (2001). Copyright 2001 American Geophysical Union. Fig. 7a was reproduced/modified by permission of American Geophysical Union.)

et al. (1998) models during the NEM (Figs. 9 and 10(a) and (b)), manifesting as a strong detrainment bloom throughout the basin in February-March following the relaxation of the winds. While this detrainment bloom associated with the NEM-SIM transition is apparent in remote chlorophyll observations (Fig. 11(d)-(f)), its magnitude relative to phytoplankton concentrations of the NEM is overstated in both models. Rather, phytoplankton biomass and production tend to be elevated throughout the winter due 
Surface Chlorophyll a observed by SeaWiFS
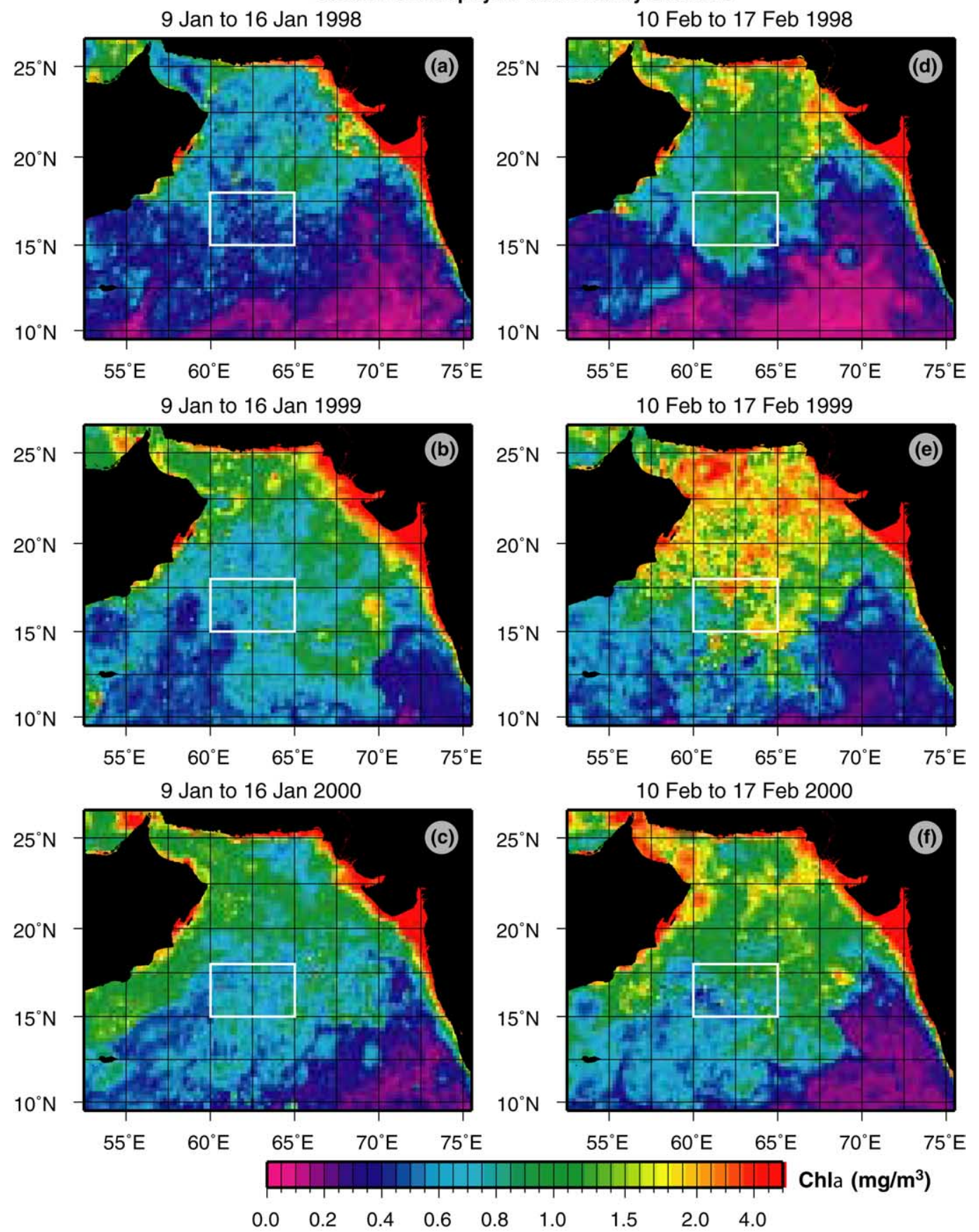

Fig. 11. Three-year comparison of chlorophyll- $a$ distributions observed by SeaWiFS during the NE Monsoon. These are 8-day composite images from the level 3, global area coverage data and were obtained from the Goddard DAAC (http://daac.gsfc.nasa.gov/). Box 3 (see Fig. 1), acts as a focus on the central Arabian Sea. The January imagery highlight the interannual variation in the NEM phytoplankton bloom, while the February imagery highlight the bloom's intensification brought on by the stratification that develops as part of the transition to the SIM. (Reprinted from Wiggert et al. (2002), Fig. 2, with permission from Elsevier \#J023.) 
to mixing and entrainment of nutrients from depth (Fig. 11(a)-(c), Banse, 1994; Marra et al., 1998). It is worth noting here that while McCreary et al. (1996) employed a simple nutrient-phytoplankton-zooplankton-detritus (NPZD) ecosystem formulation, Ryabchenko et al. (1998) utilized a more complex ecosystem model that specifically included the microbial loop (Fasham, Ducklow, \& McKelvie, 1990). The similarity in the solutions of these two modeling studies suggests that the noted shortcomings in simulated bloom dynamics cannot be attributed to ecosystem complexity. Instead, it appears that these deficiencies resulted from a combination of factors that includes: (1) the use of climatological forcing that results in an overly smoothed seasonal cycle of the mixed layer; (2) the absence of a diurnal cycle that prevents diurnal nutrient pumping and surface layer biomass dilution (see Section 6.1); and (3) overly deep mixing during the monsoons and/or incorrect specification of some of the phytoplankton light response parameters that overly inhibit phytoplankton growth in the model (McCreary et al., 2001).

\subsection{Offshore transport of nutrients from the coastal zone versus open-ocean upwelling}

As detailed in Section 4.2, there was considerable debate in the early 1990s about what mechanism(s) provided nutrients to support the observed offshore phytoplankton blooms. McCreary et al. (1996) argued that mixing and entrainment were the primary sources of nutrients in offshore waters during the SWM, with nutrients advected from the Omani and Somali coastal zones acting as an additional, secondary, source. They argued further that open-ocean upwelling was not a significant source of nutrients for the offshore bloom during the SWM. In retrospect, it is clear that in their earlier modeling study, McCreary et al. (1996) substantially underestimated the nutrient contribution provided by offshore advection during the SWM. This has been attributed to the fact that their model does not resolve mesoscale processes and filaments emanating from the coast (Hood, Kohler, McCreary, \& Smith, 2003).

The importance of mesoscale eddy variability and offshore transport from the Omani coastal zone via filaments during the SWM was not fully appreciated in the early 1990s (though see Sections 3.1 and 4.2), despite considerable evidence in both the satellite data (SST and chlorophyll) and early tracer model studies (Gallacher \& Rochford, 1995). Using a high-resolution basin-scale model coupled to a simple biological model, Young and Kindle (1994) were the first to clearly demonstrate the potential importance of mesoscale variability, filaments and offshore advection from the coastal zone in determining patterns of silicate in surface waters, both near the coast and offshore, during the SWM. They argued that offshore jets are significant transporters of nutrients to open waters from coastal upwelling areas. Keen, Kindle, and Young (1997) extended the results of Young and Kindle (1994) to investigate the effects of transported nitrate and biomass. We now know, thanks to the intense field studies of the 1990s, that the conclusions drawn from these modeling studies were largely correct.

More recent modeling work has shown that during upwelling-favorable conditions, filaments are generated by the interaction of two counter-rotating eddies with the coastal circulation along the eastern portion of the Arabian Peninsula (Kindle et al., 2002). These results are reminiscent of features that have been studied in other coastal upwelling regions (e.g., along the western coasts of the US and Peru). The effect(s), if any, of the coastal upwelling off southwest India and upsloping of sub-thermocline water onto the shelf along the entire Pakistani and Indian coasts on open-sea phytoplankton concentrations and production have not been studied in any detail.

\subsection{The data situation}

In summary, in the period just prior to the JGOFS Arabian Sea Process Studies (ASPS) some significant advances in our understanding were made through several early efforts in biogeochemical modeling. These include an appreciation of the fundamental physical mechanisms underlying bloom dynamics and advances in our understanding of the relative importance of different nutrient supply mechanisms that fuel the 
region's phytoplankton blooms. However, these early efforts were also severely hampered by the lack of data available for model validation. We now know that some aspects of the model results were unrealistic. In particular, the large-scale biogeochemical modeling studies lacked sufficient spatial resolution to simulate the mesoscale processes generating the observed biogeochemical variability. In addition, obtaining accurate forcing fields to apply as surface boundary conditions for these models has been, and continues to be, problematic. However, as the NOGAPS-Mooring comparison demonstrates (see Section 2.1) and with the ongoing collection of high-resolution wind fields (e.g., QuickScat), and concomitant improvements in the accuracy of atmospheric models and surface forcing sets, this limitation is being addressed.

\section{Developments since the JGOFS Arabian Sea Process Studies}

\subsection{The delicate balance between mixing depth, nutrient availability and light limitation}

As noted in Section 4.1, in situ light levels in the Arabian Sea exhibit a semiannual behavior with minimum irradiances occurring during the SWM and NEM. These minima are associated with cloudiness and boreal winter insolation, respectively (Arnone, Ladner, La Violette, Brock, \& Rochford, 1998), in addition to phytoplankton concentrations, and they coincide with the semiannual deepening of the bulk mixed layer. Thus, during the monsoons, nutrients are entrained into a deepening mixed layer while the corresponding light levels are relatively low, though not so low as to prevent positive net photosynthesis in the mixed layer. Under these conditions, the superposition of active diurnal mixing upon the bulk surface mixed layer (Fig. 4) subjects the phytoplankton population to highly variable light and nutrient conditions, as the diurnal mixed layer entrains and detrains over a $24-\mathrm{h}$ period. As a result, relatively small errors in a model's reproduction of absolute mixed layer depth (MLD) and/or MLD-variability can result in major errors in the primary production and bloom dynamics. Inappropriately defined light-response parameters in the phytoplankton growth equation can be equally problematic. As noted in Section 5.1, these kinds of errors were, at least in part, responsible for the deficiencies in the McCreary et al. (1996) and Ryabchenko et al. (1998) solutions. The phytoplankton population's sensitivity to such subtle interactions among MLD, MLD-variability and in situ irradiance is a unique aspect of the central Arabian Sea's physical-biological dynamics that has been a focal point of several recent modeling studies (McCreary et al., 2001; Hood et al., 2003; Wiggert et al., 2000; Wiggert, Murtugudde, \& McClain, 2002).

In a study focused on the mechanisms of the NEM phytoplankton bloom, Wiggert et al. (2000) used observations from the central mooring and a 1D coupled bio-physical model to show the importance of diurnal forcing in defining both the surface concentration and vertical distribution of chlorophyll- $a$. This model also reproduced the accumulation of nitrate in surface waters that occurs during the NEM phytoplankton bloom (Fig. 11(a)-(c)), as demonstrated by McCarthy, Garside, and Nevins (1999). The diurnally cycling mixed layer is the fundamental mechanism creating a phytoplankton bloom that does not fully develop, so that there is an associated, coincident increase in nitrate concentration. As the mixed layer shoals to $\sim 15 \mathrm{~m}$ during the day and then homogenizes all biogeochemical constituents through the upper $100 \mathrm{~m}$ at night (Fig. 4), it dilutes the surface concentration of phytoplankton accumulated in daytime, preventing a full-fledged bloom, and transports a significant fraction of the phytoplankton biomass below the euphotic zone (Gardner, Gundersen, Richardson, \& Walsh, 1999), where losses due to grazing and remineralization are more pronounced. Wiggert et al. (2000) also established that the subsequent utilization of ammonium derived from this remineralization resulted in $f$-ratios of $\sim 0.15$, consistent with the observed values based on rates of nutrient uptake (McCarthy et al., 1999).

In a subsequent study using model-extracted thermocline depth and SeaWiFS chlorophyll data from the central Arabian Sea, Wiggert et al. (2002) explored a previously postulated mechanism for generating the observed interannual variability in the wintertime (NEM) phytoplankton bloom (Fig. 11). They 
demonstrated that higher chlorophyll concentration coincided with a shallower thermocline, a relationship that directly contradicts the Bermuda paradigm. During the NEM, a deeper thermocline allows deeper diurnal mixing, which results in greater daily dilution of euphotic zone phytoplankton biomass and stronger inhibition of bloom development (see Fig. 9 in Wiggert et al., 2002). Kumar et al. (2001b) also investigated interannual chlorophyll variability (NEMs of 1995 and 1997) and concluded that the Bermuda paradigm was operating. However, their analysis was based on Indian JGOFS observations dating from 10 February onward and, therefore, should be considered to belong to the transition from the NEM to the SIM, and actually represents the spring detrainment bloom described in Section 5.1. Such a postNEM detrainment bloom also manifests in the central region (Box 3) that was the focus of both the CZCSand SeaWiFS-based analyses of interannual variations in wintertime phytoplankton concentrations (Banse \& McClain, 1986; Wiggert et al., 2002).

In a follow up study to their earlier work, McCreary et al. (2001) modified their model configuration to include the diurnal solar radiation cycle and explored how the application of high frequency forcing impacted their model results. In doing so, they developed additional insights into the importance of diurnal mixed layer cycling that extended beyond the NEM-season to include the full seasonal cycle. McCreary et al. (2001) also focused on the central mooring location where high-resolution forcing data (Weller et al., 1998) and bio-optical measurements of phytoplankton biomass and estimates of primary production (Dickey et al., 1998; Marra et al., 1998) were available for both model forcing and validation. With high-resolution forcing, the simulated bloom dynamics during the monsoons become much more complex (Fig. 10c), with rapid changes in mixed layer depth producing a series of blooms during both monsoons (NEM and SWM). This result directly contrasts with the single weak entrainment bloom at the onset of the winds and a single strong detrainment bloom when the winds relax at the end of the SWM that characterized the solution of the same model with climatological forcing (McCreary et al., 1996). The inclusion of a diurnal cycle lengthens the period during which the mixed layer is thick and significantly alters the timing of the blooms. The authors concluded that it is not possible to model biogeochemical variability in the Arabian Sea realistically using low resolution climatological forcing and that the inclusion of a diurnal cycle is crucial. Both are required to reproduce more correctly both the dynamics and timing of the region's phytoplankton blooms.

The diurnal change of mixed layer depths does not impact regions where sub-mixed layer waters are stratified to a greater degree because of salinity gradients, as during the SWM upwelling off Arabia and southwest India, or during the NEM in the southeastern Arabian and Laccadive Seas when low-salinity water is being advected from the east (Goes et al., 1992).

\subsection{Source mechanisms for mixed layer nutrients in offshore waters}

The question of the relative role of open-ocean upwelling in driving phytoplankton production and bloom formation in the central Arabian Sea during the SWM has, perhaps, finally been laid to rest. Using an eddy-permitting, biological-physical coupled model, Kawamiya (2001) showed that horizontal advection was a prominent source of offshore nutrients. In analyzing his model solution, three categories of horizontal transport were identified: (1) open-ocean upwelling driven by Ekman transport; (2) transport by the large-scale circulation and; (3) transport by the mesoscale currents. The relative contributions of these mechanisms were quantified and it was demonstrated that the latter two processes are of comparable magnitude, whereas open-ocean upwelling plays a minor role. Kawamiya (2001) also defined three source regions that consisted of the Somali coast, the Omani coast and the open ocean, Ekman pumping region north of the Findlater Jet. This allowed partitioning of the nutrient source regions, and it was found that the two coastal regions dominated, with the Omani upwelling supplying nutrients to the northern Arabian Sea and the Somali upwelling being the dominant supplier to the central Arabian Sea. The latter characterization supports the conclusions of Kumar et al. (2001a) that were based on their analysis of monthly AVHRR data. 
As noted in Section 5.2, McCreary et al. (1996) have earlier identified entrainment via mechanical mixing as the primary source of nutrients for the offshore SWM bloom. It is worth reiterating here that Lee et al. (2000) demonstrated that deepening of the offshore nitracline by downward Ekman pumping is not so drastic as reported by Bauer et al. (1991), which supports the likelihood of wind-driven entrainment as a viable mechanism for nutrient supply. McCreary et al. (1996) further advocated that eastward horizontal advection, excretion and remineralization helped maintain elevated surface layer nutrient concentrations in offshore waters, though it should be remembered that horizontally advected nutrients were under-represented in their model. Given this shortcoming and the more recent analyses summarized above, we conclude that during the SWM horizontal advection and wind-driven entrainment combine as the primary agents of nutrient supply for the offshore phytoplankton bloom. Indeed, both McCreary et al. (1996) and Kawamiya (2001) concluded that these blooms in the central Arabian Sea were in part supported by nitrate-enriched waters driven by the Great Whirl, an annually recurring cyclonic gyre typically centered at $8^{\circ} \mathrm{N}, 52^{\circ} \mathrm{E}$ off the coast of Somalia (Fig. 1).

In contrast, during the NEM the direction of the winds along the Arabian coast is downwelling-favorable, while the temperature and relative humidity of these northeasterly winds stimulate deep convective mixing (see Section 2.2.3). Under these circumstances, entrainment is the predominant source of nutrients for the observed wintertime phytoplankton blooms in offshore waters (Banse, 1987; Banse \& McClain, 1986; Madhupratap et al., 1996; Wiggert et al., 2000). A couple of fundamental questions that arose when analyzing both in situ and satellite-based phytoplankton distributions for the NEM-season (Box 3 in Fig. 1) are (1) "Why is there no prominent bloom, similar to that observed farther north?" and (2) "Why does interannual variability in wintertime bloom intensity go against the causal relationship of the Bermuda paradigm at times?" We now recognize that this NEM bloom is held in check by light limitation from the mixed layer's diurnal cycling and the depth of the permanent pycnocline. In addition, interannual variability in surface chlorophyll- $a$ concentration reflects the depth of this permanent pycnocline (i.e., the depth to which the mixed layer penetrates at night) and the associated degree of light limitation, not the amount of nitrate entrained into the euphotic zone.

\subsection{A need to resolve open-ocean eddy variability (eddies really matter)}

A major realization that has emerged from the ASPS is the prevalence of open-ocean eddies in the central Arabian Sea and that the passage of these eddies influences biogeochemical properties over the entire water column (Dickey et al., 1998; Honjo, Dymond, Prell, \& Ittekkot, 1999; Marra et al., 1998). Two major eddy-passage events were evident at the central mooring during the US JGOFS ASPS, one in the fall during the early part of the 1994 NEM, and a second one during summer in the middle of the 1995 SWM. Passage of these eddies coincided with major perturbations to the seasonal signal in moored physical and bio-optical properties (Dickey et al., 1998; Fischer et al., 2002; Marra et al., 1998), as well as perturbations in the magnitude of particle flux into nearby sediment traps (J4 on Fig. 1 or MS4 in Honjo et al., 1999). Mixed layer depths shoaled dramatically, chlorophyll concentrations increased, and particle fluxes increased in response to both events. Indeed, a large fraction of the annual export flux signal was attributed to these eddypassage events (Honjo et al., 1999). It may, in fact, be appropriate to consider that in the central Arabian Sea, the increased production and export during the monsoon periods is largely a response to increased eddy kinetic energy, especially during the SWM.

Nonetheless, recent coupled modeling studies carried out by Hood et al. (2003) and Wiggert, Murtugudde, and Christian (2004) show that much of the large-scale biogeochemical variability can be captured with non eddy-resolving models. In particular, both models successfully reproduce mean levels of primary production and export, without generating the observed eddy variability. Hood et al. (2003) concluded that the primary discrepancies between their model and the ASPS observations could be attributed to the lack of mesoscale eddy variability in their model. For example, their model does not capture major export events 
associated with passing mesoscale eddies. Yet by modifying the applied remineralization rate, Hood et al. (2003) reproduced the observed mean flux, the difference in detrital export between the NEM and SWM, and the general offshore reduction in particle flux (Fig. 12).

Even eddy-permitting (e.g., Kawamiya, 2001; Kawamiya \& Oschlies, 2003) and eddy-resolving (Haugen, Johannessen, \& Evensen, 2002) models cannot be expected to reproduce the location and timing of specific biogeochemical events. In order to accurately depict mesoscale variability in the ocean interior, assimilation of satellite-observed SST and SSH (sea surface height) into eddy-resolving ocean general circulation models will be a necessity (Rochford, Kindle, Gallacher, \& Weller, 2000). In an encouraging recent development, the results of Kindle et al. (2002) reveal that real-time global models now have the resolution and data assimilation skill to accurately represent mesoscale variability in the northern Arabian Sea. Hindcast experiments using the global operational Navy Layered Ocean Model (NLOM; Rhodes et al., 2002) at 1/16th degree resolution demonstrated reasonable agreement with the observed filaments and eddy field during
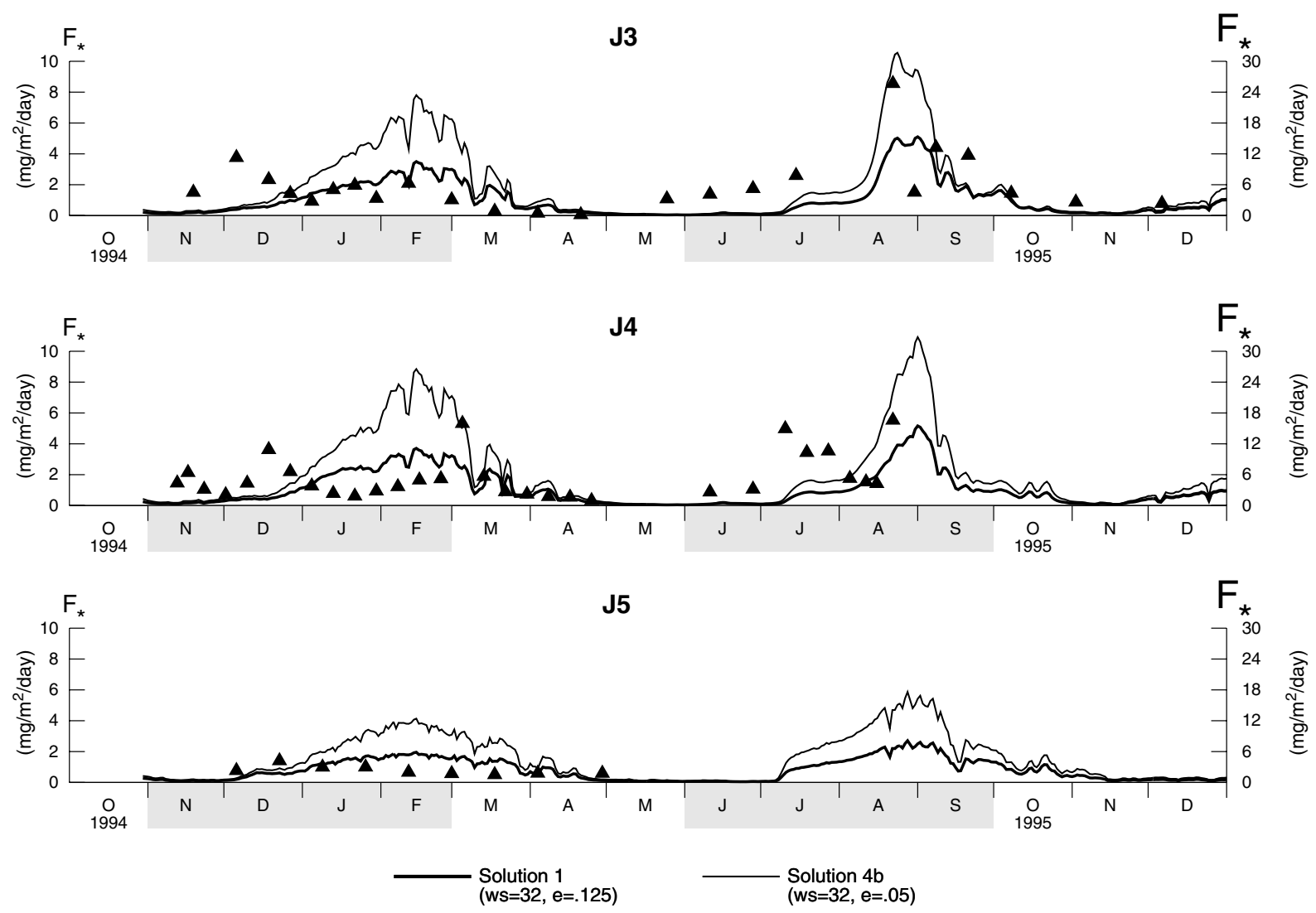

Fig. 12. Model-generated time series of detrital fluxes $F^{*}\left(\mathrm{mg} \mathrm{N} / \mathrm{m}^{2} /\right.$ day) at the three southernmost Arabian Sea Process Study sediment-trap sites from Hood et al. (2003) along with measured fluxes (triangles) from sediment traps at 800-900 m (left axis scale). The sites from which the offshore $\mathrm{F}^{*}$ time series labeled J4 and J5 were obtained (see Fig. 1) are near the US JGOFS sites S7 and S15 (Smith et al., 1998). The $F^{*}$ time series labeled J3 is more prominently impacted by mesoscale eddies and is near to US JGOFS hydrographic station S4. Note that these trap identifiers (J3-J5) coincide with the sediment traps labeled MS3-MS5 in Honjo et al. (1999). Two model solutions are shown with the same sinking rate $(w s=32 \mathrm{~m} /$ day) and different values of detrital remineralization rate (e) consisting of $e=0.125 \mathrm{day}^{-1}$ (thick line, left axis scale) and $e=0.05 \mathrm{day}^{-1}$ (thin line, right axis scale). The grey-shaded regions on the time axis indicate the approximate time-periods of the monsoons. (Reprinted from Hood et al. (2003), Fig. 4, with permission from Elsevier \#J023.) 
the SWM of 1995, but no systematic comparisons with the WHOI buoy measurements have been conducted yet. Fig. 13 depicts a more recent example that shows excellent correspondence between NLOM-simulated structure in the physical environment for October 3, 2002, and the observed ocean color distribution from Terra MODIS (Moderate Resolution Imaging Spectroradiometer; http://modis.gsfc. nasa.gov), composited for the period September 29-October 7, 2002. This recent improvement in the representation of individual mesoscale features within physical models bodes well for future advances in modeling coupled physical-biogeochemical variability in the Arabian Sea and elsewhere.

\subsection{Potential importance of higher order biogeochemical complexity}

\subsubsection{Grazing and zooplankton behavior}

An interesting hypothesis that has emerged is that phytoplankton biomass and primary production could be regulated by seasonal redistribution of diapaused copepods via advection. During the SWM, ontogenetically migrating species, such as Calanoides carinatus and Subeucalanus crassus, appear in the surface layers early in the upwelling season (Smith et al., 1998), and it has been hypothesized that they provide grazer control of diatom blooms (Smith, 2001). Hood et al. (2003) suggest that explicitly simulating such behavior could allow zooplankton in their model to reduce the magnitude of the phytoplankton blooms that develop in response to coastal upwelling during the SWM. Due to the inefficiency of copepods in successfully capturing picoplankton, such a mechanism would principally affect the larger sizes of phytoplankton, consistent with the classical four-component, diatom-mesozooplankton structure of the Hood et al. (2003) ecosystem. At present, their model tends to overestimate the magnitude of the coastal blooms, though another likely source for this overestimate is that offshore advection is presently underrepresented (see Section 6.3).

Idrisi, Olascoaga, Garrafo, Olson, and Smith (2004) studied this seasonal redistribution of C. carinatus using a regional isopycnal model with zooplankton represented as Lagrangian particles that were initially released off the Somali coast at depths that ranged from 500 to $1200 \mathrm{~m}$. Among other things, they showed that

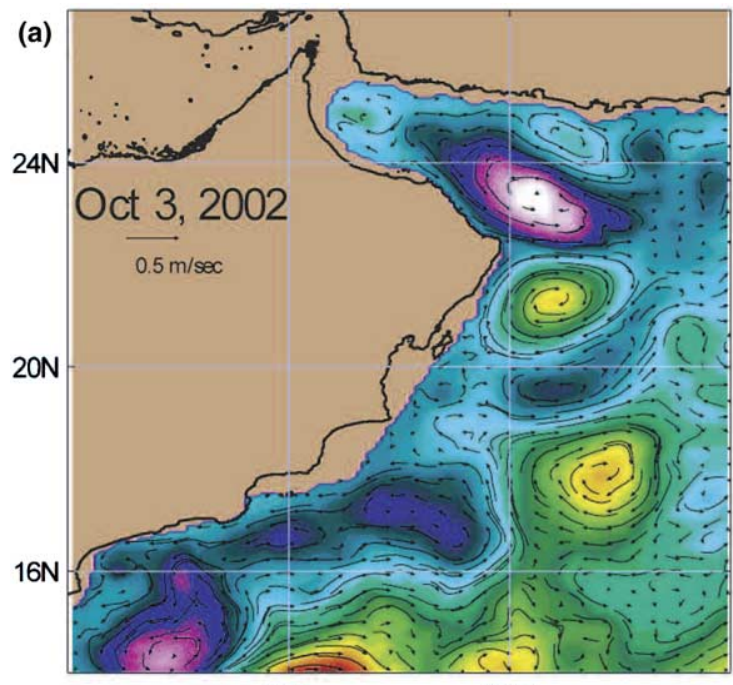

$56 \mathrm{E}$

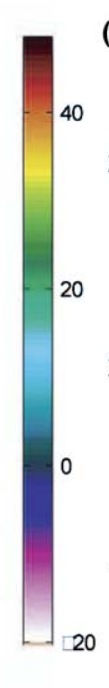

$60 \mathrm{E}$

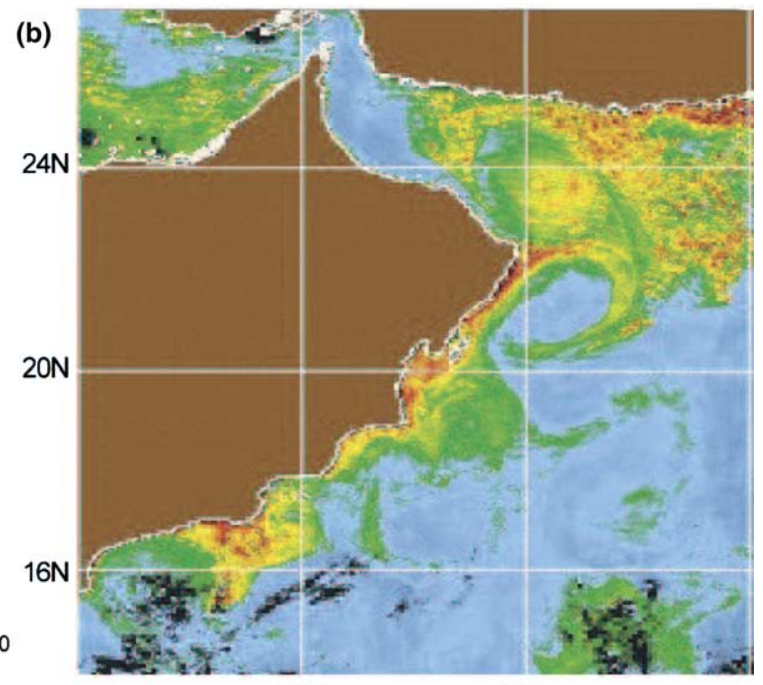

$56 \mathrm{E}$

$60 \mathrm{E}$

Fig. 13. (a) Snapshot for October 3, 2002 of surface currents with model Sea Surface Height from the Navy's operational NLOM (Navy Layered Ocean Model) model; the model has 1/16th degree resolution and assimilates MCSST (multi-channel sea surface temperature) and altimeter-derived sea level fields. (b) Composited Terra MODIS (MOderate Resolution Imaging Spectroradiometer) ocean color image of Diffuse Attenuation Coefficient at $532 \mathrm{~nm}$ for period September 29-October 7, 2002 (image courtesy of R. Arnone, NRL). 
the depth at which the copepods reside during diapause plays a crucial role in determining retention and dispersal. Their model results suggest that overwintering in deeper layers $(>800 \mathrm{~m})$ will result in greater retention in the feeding area of the coastal zone, with emergence from diapause being triggered by an internal mechanism. In contrast, for copepods overwintering at shallower depths emergence from diapause can be triggered by external cues. However, they are subject to a more dispersive environment and are more likely to be transported out of the coastal zone and into the central Arabian Sea where successful emergence is less assured.

\subsubsection{The oxygen minimum zone}

There are very few published biogeochemical modeling studies of the Arabian Sea's oxygen minimum zone $(\mathrm{OMZ})$. This is surprising since it is one of the three major denitrifying regions of the world's oceans; it exhibits globally significant losses of dinitrogen gas $\left(\mathrm{N}_{2}\right)$ to the atmosphere; and its features within the Arabian Sea's pelagic system have been relatively well characterized (Bange, Naqvi, \& Codispoti, 2005; Naqvi, Naik, \& Narvekar, 2003; Naqvi et al., 2005). The processes associated with the maintenance of the OMZ in the Arabian Sea are thought to include slow advection of intermediate waters, high respiration rates related to the elevated primary productivity in surface waters, and influx of low oxygen waters from the south (Swallow, 1984; Warren, 1994). Based upon residence times calculated using the transient anthropogenic trace gas trichlorofluoromethane, Olson, Hitchcock, Fine, and Warren (1993) suggested that the $\mathrm{OMZ}$ is maintained by a combination of the factors just noted, and recent estimates suggest a time-scale of $\leqslant 10$ years (Howell, Doney, Fine, \& Olson, 1997; Naqvi, 1987).

Yakushev and Neretin (1997) applied a 1D model of the nitrogen and sulfur cycles and oxygen distributions to the Arabian Sea that produced vertical distributions of nitrogen and sulfur compounds and dissolved oxygen concentrations that agreed reasonably well with observations. This was a surprising result, because it suggests that horizontal advection is not involved in the maintenance of the Arabian Sea's OMZ. However, they did not fully represent the biogeochemical system, as fluxes of oxygen and the various organic and inorganic species of nitrogen and sulfur were specified only at the upper and lower boundaries of the model domain. More recently, Naqvi (2001) demonstrated that the region of most intensive denitrification, as indicated by high nitrite concentrations, does not spatially coincide with regions of highest primary production, lending support to the contention that the OMZ cannot be interpreted without considering horizontal advection. The configuration of the intense eddy field during the SWM could contribute to the spatial separation of areas of high primary productivity and the OMZ (Kim et al., 2001).

Sarma (2002) constructed monthly oxygen budgets for the subsurface Arabian Sea using transports calculated by a 3D circulation model and observed oxygen concentrations. This study, though technically not based upon a coupled biogeochemical model, suggested that the maintenance of the OMZ during the SIM and FIM periods, when export of organic matter from the surface waters is low, occurs primarily through reduced supply of oxygen via horizontal advection. In contrast, during the monsoons the high export of organic matter is counterbalanced by a more vigorous circulation and greater horizontal advection and ventilation. Thus, the seasonal persistence of the Arabian Sea OMZ can be attributed to changes in biological oxygen demand in intermediate waters that occur in tandem with changes in horizontal advection and ventilation. Both are driven by the seasonal monsoon cycle, and they have counteracting effects. Clearly, further modeling and observational studies are needed to better understand the factors that contribute to the maintenance of the Arabian Sea's OMZ.

\subsubsection{Ecosystem complexity}

Analyses of the comprehensive observations made during the JGOFS field campaigns have led to significant insights into the seasonal and spatial variations in pelagic ecosystem structure that occur in response to monsoonal forcing (Campbell et al., 1998; Garrison et al., 2000; Shalapyonok, Olson, \& Shalapyonok, 2001; Tarran, Burkill, Edwards, \& Woodward, 1999). The pronounced spatial heterogeneity associated with coastal filaments and mesoscale eddies during the SWM has also received attention (Garrison, Gow- 
ing, \& Hughes, 1998; Latasa \& Bidigare, 1998). However, for the most part, biogeochemical modeling studies covering the Arabian Sea region to date have employed simple, nitrogen-based ecosystem models and have yet to address newly emerging details relating to species composition, community structure, particle aggregation and variable nutrient uptake rates.

Blackford and Burkill (2002) applied a complex, multi-species, variable elemental ratio ecosystem model coupled to a 1D turbulence closure model at three contrasting stations. They successfully reproduced the observed transition from more productive food web dynamics dominated by diatoms and mesozooplankton during the monsoon periods to a more oligotrophic, microbial loop dominated system during the intermonsoon periods, as well as increasing oligotrophy away from the Omani coast. The model also predicted that small-celled phytoplankton would be dominant and that DCMs were robust centers of production during the intermonsoon periods, as observed (Barlow et al., 1999; Woodward, Rees, \& Stephens, 1999). Although much of the validation work in their study relied on traditional, bulk measurements of biomass and production, Blackford and Burkill (2002) made more extensive use of the data available from the JGOFS cruises on size-structure and plankton community composition compared to most other modeling efforts. Despite its 1D character, the model reproduces many aspects of the observed variability, confirming the importance of vertical processes, such as mixing and entrainment, in driving biogeochemical variability in the Arabian Sea.

\subsubsection{Iron's role as a micronutrient}

In a 3D coupled model, Wiggert et al. (2004) include large and small size classes of phytoplankton, zooplankton and detritus as well as explicit iron biogeochemistry. The latter ecosystem model component has allowed for some interesting new insights into the role that iron may play in the Arabian Sea. Their results suggest that the region undergoes a marked seasonal evolution in the spatial extent of areas that tend toward nitrogen limitation versus those that tend toward iron limitation, based on the relative concentrations of these two constituents in the model's surface layer. In their standard solution, waters of the Arabian Sea east of $60^{\circ} \mathrm{E}$ and north of the equator generally remain iron replete, while waters to the west of $60^{\circ} \mathrm{E}$ and north of the equator are susceptible to iron limitation. Seasonally, iron-limited waters are minimally evident during the SIM and most extensive during the SWM when they penetrate as far as $65^{\circ} \mathrm{E}$ between $5^{\circ}$ and $15^{\circ} \mathrm{N}$. Since sub-thermocline waters in the model are initialized with a higher N:Fe ratio than that applied to the surface layer, the model's pattern of most limiting nutrient primarily reflects the magnitude of coastal upwelling and the subsequent offshore redistribution of upwelled waters by horizontal advection. The distribution of iron-limited waters in the Wiggert et al. (2004) solution clearly indicates that the Somali coast is the predominant upwelling source and that the Great Whirl plays a pivotal role in driving the offshore redistribution, which further supports the conclusions of previous studies regarding nutrient sources to the central Arabian Sea (Kawamiya, 2001; Kumar et al., 2001a).

Furthermore, through the application of two distinct aeolian flux boundary conditions, recent model results indicate that the dust-source regions of eastern Africa and Arabia may contribute to the evolution of the SWM's offshore phytoplankton blooms (Wiggert et al., 2004). In their standard run, estimates of aeolian iron deposition were derived from the GOCART (Global Ozone Chemistry and Atmospheric Transport) model, which better represents the above noted dust sources (Ginoux et al., 2001). Fig. 14 shows surface chlorophyll distributions for July for the standard solution (Fig. 14(a)) and the corresponding distribution when the aeolian flux boundary condition derived from the GISS (Goddard Institute for Space Studies) model (Tegen \& Fung, 1994) was applied (Fig. 14(b)). When compared to the July image from the SeaWiFS climatology (Fig. 6(c)), it can be seen that offshore concentrations of surface chlorophyll- $a$ (i.e., in Box 2 of Fig. 1) are much better represented in the standard solution. Moreover, a shift toward the larger phytoplankton size and a doubling of export production accompany appearance of this offshore, SWM bloom in the model when the GOCART-derived deposition is applied. While supporting the notion that the Arabian Sea is not iron limited due to the high dust deposition rates (Measures \& Vink, 1999; 

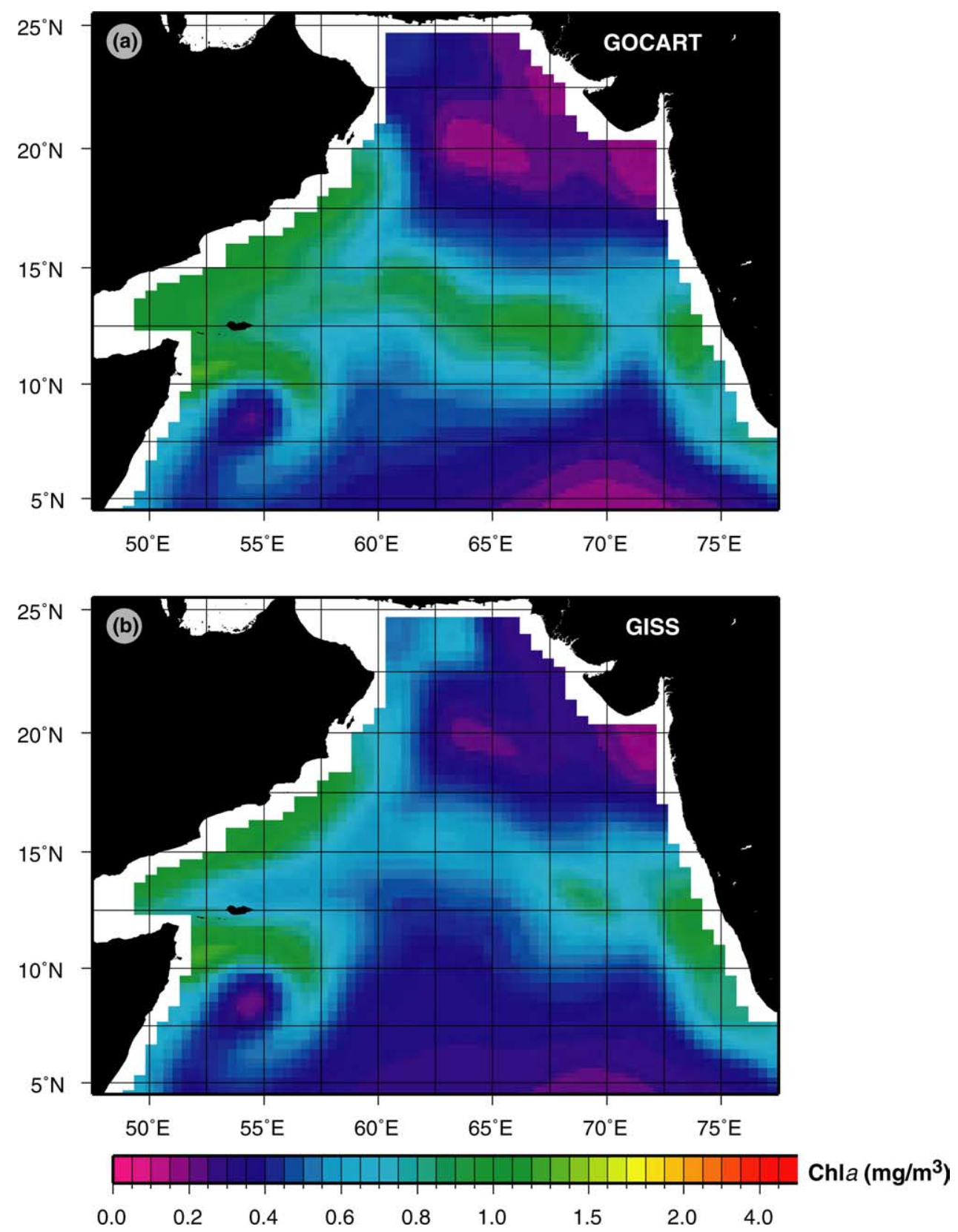

Fig. 14. Comparison of modeled surface chlorophyll- $a$ distribution for July where aeolian iron flux conditions derived from two separate atmospheric transport models. (a) Solution obtained when applying the GOCART-derived flux condition. (b) Solution obtained when applying the GISS-derived flux condition. The GOCART model better represents the dust sources in eastern Africa and Arabia.

Smith, 2001), these results suggest that the pattern of aeolian deposition helps regulate the appearance and distribution of offshore phytoplankton blooms during the SWM and should be included along with the mechanisms presented in Sections 4.2 and 6.2 when considering this feature's development. 


\section{Remaining challenges and future directions}

\subsection{We still do not have enough data}

An underlying theme of this review is that in situ and remote sensing observations provide a major impetus for new biogeochemical modeling studies, as new phenomena are uncovered. Both are also crucial for validating model results. The combination of remote sensing, the Arabian Sea Process Studies and new modeling efforts have resulted in major advances in our understanding of this unique ocean region in recent years. Nonetheless, our models and our general understanding of the Arabian Sea ecosystem are still constrained by the presently available biogeochemical observations, as much as by the need to understand the responses to coastal upwelling in the SWM and year-round physical variability associated with the mesoscale eddy field. Correcting this deficiency requires continuous timeseries measurements and unambiguous remote sensing estimates of surface chlorophyll concentration during the SWM.

From a modeling point of view, it would be extremely valuable to have additional mooring-based physical and bio-optical observations extending from the coastal zone to the central Arabian Sea, in a configuration similar to the deployment of the ASPS sediment traps (Honjo et al., 1999). In addition, the problems of aerosol contamination and cloud cover for remote chlorophyll estimates are major impediments to advancing our understanding of the time-space variability of phytoplankton biomass. Successful data retrievals are highly problematic during the SWM and severely limit our ability to characterize the temporal and spatial evolution of the period's extensive phytoplankton blooms (note Fig. 6(c), Fig. 7, and gaps in the time-series in July in Fig. 8). The recent work by Banzon et al. (2004) that makes use of an alternative ocean color algorithm (see Section 3.3), shows great potential for revealing the phytoplankton blooms of the SWM.

In their status report on the planning of the US JGOFS Arabian Sea program, Codispoti and Smith (1994) posed the following questions regarding aeolian fluxes: (1) How important are aeolian fluxes in supporting the productivity of the Arabian Sea? (2) Do these fluxes influence phytoplankton species composition? and (3) How will they affect the algorithms that must be developed to interpret data from SeaWiFS? While the latter question has been actively pursued (as just noted and discussed in Section 3.3), the first two questions remain largely unaddressed. The model results of Wiggert et al. (2004) strongly suggest that offshore phytoplankton distributions are highly sensitive to the magnitude and distribution patterns of aeolian iron flux. However, few data are available for characterizing the distribution of bioavailable, dissolved iron in the Arabian Sea. Such observations would help us to develop better-characterized fields to further our modeling efforts and for tackling the first two questions, posed a decade ago.

\subsection{What level of ecosystem complexity do we need to simulate?}

The Blackford and Burkill (2002) study (Section 6.4.3) begs the question: What level of ecological complexity is required to simulate the observed biogeochemical variability in the Arabian Sea? This is an important issue that is directly relevant to many ongoing modeling efforts. Some of these efforts employ relatively simple ecosystem formulations (e.g., Hood et al., 2003; Kawamiya \& Oschlies, 2003; Keen et al., 1997), whereas others employ highly complex biogeochemical models (e.g., Blackford \& Burkill, 2002; Moore, Doney, Kleypas, Glover, \& Fung, 2002), while still others apply a compromise between these extremes (e.g., Swathi, Sharada, \& Yajnik, 2000; Wiggert et al., 2004). At present our greatest challenge in modeling the Arabian Sea involves reproducing the observed levels of physical variability (e.g., upwelling and rapid mixing events, filaments and mesoscale eddies). These higher frequency physical processes are directly responsible for major biogeochemical events that are, in turn, responsible 
for a large fraction of the annual production and export fluxes, especially shoreward of the axis of the Findlater Jet. Until these processes are resolved and their biogeochemical effects accounted for, our understanding of Arabian Sea biogeochemical variability is likely to be less significantly impacted by the incorporation of added ecosystem model complexity than in other oceanic regions with less dynamic physical environments. This point of view is substantiated by the similarity in bloom dynamics resolved by the two earliest large-scale modeling studies of the Arabian Sea discussed in Section 5.1, despite their significantly different ecosystem formulations. On the other hand, the clear sensitivity to aeolian deposition pattern (Fig. 14) demonstrates that additional ecosystem model complexity can advance our understanding of offshore biogeochemical processes.

The ongoing analyses of Friedrichs, Hood, and Wiggert (2002) also suggest that our biogeochemical models are at present limited by our ability to simulate the physical environment. The goal of the Friedrichs et al. (2002) study is to quantitatively compare the performance of the various ecosystem models that have been developed to simulate and study biogeochemical processes at the six US JGOFS Process Study and time-series sites. In order to carryout these comparisons, identical physical forcing is applied and the ecosystem models are objectively optimized. Identical physical environments are achieved by running all models in a $1 \mathrm{D}$ framework using forcing time-series derived from either moored observations or output from 3D circulation models. Objective optimization is accomplished by applying the variational adjoint method of data assimilation to each ecosystem model (Friedrichs, 2001; Tziperman \& Thacker, 1989). The optimized ecosystem models can then be compared quantitatively to assess which model structures best represent the fundamental underlying biogeochemical processes and which can be applied across a wide range of ocean environments without significant modification of the applied parameter set.

Friedrichs et al. (2002) describe an ecosystem model comparison in the Arabian Sea that uses forcing time-series from the central mooring and physical fields extracted from two separate 3D model simulations. It assimilates in situ biogeochemical data obtained during the ASPS. Initial comparisons involving 4-, 5-, and 8-compartment models indicate that changes in the physical environment result in more drastic changes in the resulting phytoplankton distributions than does varying model complexity. Also, deficiencies in the applied physical forcing (e.g., MLD time-series and vertical velocities extracted from the 3D model solutions) can cause the assimilation of biogeochemical measurements to yield inappropriate ecosystem model parameters that lead to unrealistic behavior. Finally, no demonstrable performance improvement is achieved with the more complex model formulations.

This last result is provocative and certainly warrants further study to ascertain whether; (a) the physical models, from which some of the environmental forcing fields were extracted, need refinement, or (b) the assimilated biogeochemical data are sufficient and diverse enough to distinguish the various aspects of the pelagic system. The latter point reinforces the need for additional observations, as called for in the previous section, with the further stipulation that these measurements be varied enough to characterize the range of upper ocean biogeochemical processes. Data that are highly correlated provide minimal further information to the assimilation scheme. The results of Friedrichs et al. (2002) pertain specifically to the utility of multiple size-classes in models, and do not address processes such as micronutrient limitation, the role of particle aggregation in export flux or the impact of variable nutrient-uptake ratios. Future applications of this technique could assess various mathematical formulations emulating biogeochemical processes. This would be similar in scope to the evaluation of zooplankton grazing functions performed by Sharada and Yajnik (1997).

\subsection{The OMZ: low oxygen biogeochemistry and its impact on carbon cycling}

Another obvious challenge in the Arabian Sea (and for large-scale, prognostic ocean modeling efforts in general) is the need to develop dynamic models that can simulate the OMZ and the major biogeochemical 
processes associated with it (Naqvi et al., 2003). The Arabian Sea is an ideal location for which to develop these models because it is strongly forced, seasonally variable and partially enclosed. Moreover, the large-scale circulation has been fairly well described and can be modeled with some degree of accuracy (Schott et al., 2002). The Arabian Sea is a globally significant region of pelagic denitrification that, over geological time-scales, plays an important role in determining the nitrogen inventory of the world ocean (see Bange et al., 2005).

Denitrification is directly relevant to the carbon cycle and carbon export because by increasing $\mathrm{N}$ limitation regionally and globally it can restrict particulate organic matter formation and export. Thus, denitrification reduces the effectiveness of the biological pump and causes significant deviation from the Redfield stoichiometry that is typically assumed. This adds an as yet unaddressed, complexity to carbon cycle modeling efforts (e.g., Swathi et al., 2000). However, we still do not fully understand, especially quantitatively, the combination of factors that give rise to, and maintain, the $\mathrm{OMZ}$ and denitrification in the Arabian Sea (see Section 6.4.2). The characteristic rates of these processes are poorly constrained (Codispoti et al., 2001), and prognostic models that could be used to predict how these rates might change in response to natural or anthropogenically induced climate change are lacking. Until we have this capability in the Arabian Sea and for other open-ocean OMZ regions, there may be little hope of predicting the long-term impact of anthropogenic carbon release and its consequences for global warming.

\subsection{Expanding our viewpoint to the basin-scale}

The anomalously low surface chlorophyll concentrations observed by SeaWiFS in the Arabian Sea during the 1997/1998 NEM (Fig. 11(a)) coincided with one of the strongest manifestations of the Indian Ocean Zonal Mode (IOZM) of the past forty years (Annamalai et al., 2003; Saji, Goswami, Vinayachandran, \& Yamagata, 1999; Yamagata et al., 2003). Briefly, the IOZM is an oceanic response to anomalous wind forcing that consists of a downward/upward shift in the equatorial thermocline in the east/west during the FIM and NEM seasons. The most prominent biological signature of the 1997/1998 IOZM was along the equator, where anomalously high concentrations of surface chlorophyll first appeared west of Sumatra in October of 1997 (Murtugudde et al., 1999). However, both the Bay of Bengal and the Arabian Sea exhibited anomalous biological distribution patterns as well (Wiggert et al., 2004). As detailed in Section 6.1, Wiggert et al. (2002) associated this anomalous behavior in the Arabian Sea with a thermocline depth that was $\sim 15$ $\mathrm{m}$ deeper than the climatological mean during the NEM. TOPEX/Poseidon altimetry suggests that this depressed thermocline may have been related to unusually weak, upwelling Rossby waves propagating westward across the Arabian Sea (see Fig. 3 in Brandt et al., 2002). The atypical character of these Rossby waves may have resulted from anomalous wind-curl conditions off the west coast of India (Brandt et al., 2002). However, it is also possible that remote forcing originating from the Bay of Bengal played a role through its influence on an anticyclonic ocean gyre (the Laccadive High) that appears off the southwest coast of India at this time (Bruce, Johnson, \& Kindle, 1994; McCreary, Kundu, \& Molinari, 1993; Shankar, Vinayachandran, \& Unnikrishnan, 2002).

Thus, regional to basin-wide connections may play an important role in determining some aspects of the observed biogeochemical variability in the Arabian Sea. This suggests that in biogeochemical modeling efforts we should consider the Indian Ocean basin as a whole, in order to fully represent coupling mechanisms between the various sub-regions. At present, the modeling study of Wiggert et al. (2004) represents the only existing attempt. Through the application of interannual forcing, such a modeling approach will provide a means of investigating among other things (1) the basin-wide biogeochemical impact of the IOZM, which is of particular interest since three such events were observed during the 1990s, and (2) the interannually varying impact of the Somali upwelling on the distribution of Arabian Sea phytoplankton blooms. 


\section{Conclusions}

The combination of both remote and in situ observation and biogeochemical modeling studies that have been carried out as part of the JGOFS activities in the Arabian Sea and the subsequent synthesis and modeling efforts has resulted in major advances in our understanding. We now have a better characterization of the time-space variability in the biogeochemical properties in the Arabian Sea and deeper insights into the physical and biological factors that drive it. Both the remote sensing and in situ observations have provided essential synoptic, process and time-series data for model development and validation, and modeling studies have helped to synthesize the data, fill in data gaps, and illuminate underlying mechanisms.

Nonetheless, major deficiencies remain, and our models must still be viewed as highly simplified representations of the Arabian Sea system. Future advances will require higher resolution models that resolve the physical and biogeochemical variability in this unique ocean environment, and more high-resolution observations will be needed to validate these models, as well as provide further impetus to hypothesis testing as new mechanisms are uncovered. Given recent advances in both observational and computing technologies, we are optimistic that these challenges will be met.

\section{Acknowledgments}

The authors thank the following for supporting their research efforts. JW was supported through the NASA Oceanography Program (NAG 58595). RH was supported through the US JGOFS Synthesis and Modeling Project of the NSF (OCE-9818708). KB was partially supported by ONR Grant N0001497-1-0120. Funding for JK was provided through the Naval Research Laboratory (NRL) 6.1 CoBALT ARI under program element $61153 \mathrm{~N}$ sponsored by the Office of Naval Research. The comments of Marjy Friedrichs, Hermann Bange and two anonymous reviewers led to significant improvements in the manuscript and are greatly appreciated. We also express our appreciation to Sharon Smith for her continuing encouragement and interest. This is US JGOFS contribution number 1038.

\section{References}

Aleem, A. A., \& Morcos, S. A. (1984). John Murray/Mabahiss expedition versus the International Indian Ocean Expedition (IIOE) in retrospect. Deep-Sea Research I, 31, 583-588.

Annamalai, H., Murtugudde, R., Potemra, J., Xie, S. P., Liu, P., \& Wang, B. (2003). Coupled dynamics over the Indian Ocean: spring initiation of the zonal mode. Deep-Sea Research II, 50, 2305-2330.

Arnone, R. A., Ladner, S., La Violette, P. E., Brock, J. C., \& Rochford, P. A. (1998). Seasonal and interannual variability of surface photosynthetically available radiation in the Arabian Sea. Journal of Geophysical Research, 103, 7735-7748.

Baker, S., Arnone, R., \& Sheres, D. (1996). Characteristics of double vortices in the northeastern Arabian Sea and the North Atlantic Gulf Stream region. EOS, Transactions of the American Geophysical Union, 77, 382.

Bange, H.W., Naqvi, S.W.A., \& Codispoti, L.A. (2005). The nitrogen cycle. Progress in Oceanography, this issue, doi:10.1016/ j.pocean.2005.03.002.

Banse, K. (1984). Overview of the hydrography and associated biological phenomena in the Arabian Sea, off Pakistan. In B. U. Haq \& J. D. Milliman (Eds.), Marine Geology and Oceanography of Arabian Sea and Coastal Pakistan (pp. 271-303). New York: Van Nostrand Rheinhold Co.

Banse, K. (1987). Seasonality of phytoplankton chlorophyll in the central and northern Arabian Sea. Deep-Sea Research I, 34, 713-723.

Banse, K. (1994). On the coupling of hydrography, phytoplankton, zooplankton, and settling organic particles offshore in the Arabian Sea. Proceedings of the Indian Academy of Sciences, Earth and Planetary Sciences, 103, 125-161.

Banse, K. (2002). Steemann Nielsen and the zooplankton. Hydrobiologia, 480, 15-28.

Banse, K., \& Anderson, G. C. (1967). Computations of chlorophyll concentrations from spectrophotometric readings. Limnology and Oceanography, 12, 696-697. 
Banse, K., \& English, D. C. (1993). Revision of satellite-based phytoplankton pigment data from the Arabian Sea during the Northeast Monsoon. Marine Research (Pakistan), 2, 83-103.

Banse, K., \& English, D. C. (2000). Geographical differences in seasonality of CZCS-derived phytoplankton pigment in the Arabian Sea for 1978-1986. Deep-Sea Research II, 47, 1623-1677.

Banse, K., \& McClain, C. R. (1986). Winter blooms of phytoplankton in the Arabian Sea as observed by the Coastal Zone Color Scanner. Marine Ecology Progress Series, 34, 201-211.

Banzon, V. F., Evans, R. E., Gordon, H. R., \& Chomko, R. M. (2002). Application of the spectral matching algorithm to the Arabian Sea SeaWiFS imagery. Ocean Optics, 16, 1-9.

Banzon, V. F., Evans, R. E., Gordon, H. R., \& Chomko, R. M. (2004). SeaWIFS observations of the Arabian Sea Southwest Monsoon bloom for the year 2000. Deep-Sea Research II, 51, 189-208.

Barlow, R. G., Mantoura, R. F. C., \& Cummings, D. G. (1999). Monsoonal influence on the distribution of phytoplankton pigments in the Arabian Sea. Deep-Sea Research II, 46, 677-699.

Barth, J. A., Cowles, T. J., Kosro, P. M., Shearman, R. K., Huyer, A., \& Smith, R. L. (2002). Injection of carbon from the shelf to offshore beneath the euphotic zone in the California Current. Journal of Geophysical Research, 107, art. no. 3057.

Bauer, S., Hitchcock, G. L., \& Olson, D. B. (1991). Influence of monsoonally-forced Ekman dynamics upon surface layer depth and plankton biomass distribution in the Arabian Sea. Deep-Sea Research I, 38, 531-553.

Bauer, S., Hitchcock, G. L., \& Olson, D. B. (1992). Response of the Arabian Sea surface layer to monsoon forcing. In B. N. Desai (Ed.), Oceanography of the Indian Ocean (pp. 659-672). New Delhi: Oxford \& IBH.

Behrenfeld, M. J., \& Falkowski, P. G. (1997). Photosynthetic rates derived from satellite-based chlorophyll concentration. Limnology and Oceanography, 42, 1-20.

Bhattathiri, P. M. A., Pant, A., Sawant, S., Gauns, M., Matondkar, S. G. P., \& Mahanraju, R. (1996). Phytoplankton production and chlorophyll distribution in the eastern and central Arabian Sea in 1994-1995. Current Science, 71, 857-862.

Blackford, J. C., \& Burkill, P. H. (2002). Planktonic community structure and carbon cycling in the Arabian Sea as a result of monsoonal forcing: the application of a generic model. Journal of Marine Systems, 36, 239-267.

Böhm, E., Morrison, J. M., Manghnani, V., Kim, H. S., \& Flagg, C. N. (1999). The Ras al Hadd Jet: remotely sensed and acoustic doppler current profiler observations in 1994-1995. Deep-Sea Research II, 46, 1531-1549.

Brandt, P., Stramma, L., Schott, F., Fischer, J., Dengler, M., \& Quadfasel, D. (2002). Annual Rossby waves in the Arabian Sea from TOPEX/POSEIDON altimeter and in situ data. Deep-Sea Research II, 49, 1197-1210.

Brink, K., Arnone, R., Coble, P., Flagg, C., Jones, B., Kindle, J., et al. (1998). Monsoons boost biological productivity in Arabian Sea. EOS, Transactions of the American Geophysical Union, 79, 168-169.

Brock, J., Sathyendranath, S., \& Platt, T. (1993). Modeling the seasonality of subsurface light and primary production in the Arabian Sea. Marine Ecology Progress Series, 101, 209-221.

Brock, J., Sathyendranath, S., \& Platt, T. (1994). A model study of seasonal mixed-layer primary production in the Arabian Sea. Proceedings of the Indian Academy of Sciences, Earth and Planetary Sciences, 103, 163-176.

Brock, J. C., \& McClain, C. R. (1992). Interannual variability in phytoplankton blooms observed in the Northwestern Arabian Sea during the Southwest Monsoon. Journal of Geophysical Research, 97, 733-750.

Brock, J. C., McClain, C. R., Luther, M. E., \& Hay, W. W. (1991). The phytoplankton bloom in the Northwest Arabian Sea during the southwest monsoon of 1979. Journal of Geophysical Research, 96, 20,623-20,642.

Bruce, J. G., Johnson, D. R., \& Kindle, J. C. (1994). Evidence for eddy formation in the eastern Arabian Sea during the northeast monsoon. Journal of Geophysical Research, 99, 7651-7664.

Calbet, A., \& Landry, M. R. (1999). Mesozooplankton influences on the microbial food web: Direct and indirect trophic interactions in the oligotrophic open ocean. Limnology and Oceanography, 44, 1370-1380.

Campbell, L., Landry, M. R., Constantinou, J., Nolla, H. A., Brown, S. L., Liu, H., \& Caron, D. A. (1998). Response of microbial community structure to environmental forcing in the Arabian Sea. Deep-Sea Research II, 45, 2301-2325.

Codispoti, L. A., Brandes, J. A., Christensen, J. P., Devol, A. H., Naqvi, S. W. A., Paerl, H. W., et al. (2001). The oceanic fixed nitrogen and nitrous oxide budgets: moving targets as we enter the anthropocene? Scientia Marina, 65, 85-105.

Codispoti, L. A., \& Smith, S. L. (1994). The US JGOFS Arabian Sea Research Program. In J. C. Goldman \& H. D. Livingston (Eds.), Biogeochemical processes in the Arabian Sea (pp. 35-46). Sevastopol: Marine Hydrophysical Institute, National Ukrainian Academy of Sciences.

Colborn, J. G. (1975). The thermal structure of the Indian Ocean (p. 173). Honolulu, HI: The University Press of Hawaii.

Conkright, M., O'Brien, T., Levitus, S., Boyer, T.P., Antonov, J., \& Stephens, C. (1998). World Ocean Atlas 1998: Nutrients and Chlorophyll of the Indian Ocean (Vol. 12, p. 217). Tech. Rep. NOAA Atlas NESDIS 38. Washington DC: US Government Printing Office.

Cutler, A. N., \& Swallow, J. C. (1984). Surface currents of the Indian Ocean (to 25S, 100E). Technical Report 187 (8 pp. and 36 charts). Brachnell: Meteorological Office, UK Institute of Oceanographic Science.

Deacon, G. E. R., \& Rice, A. L. (1984). The significance of the John Murray/Mabahiss expedition to the Arabian Sea. Deep-Sea Research I, 31, 573-581. 
Dickey, T., Marra, J., Sigurdson, D. E., Weller, R. A., Kinkade, C. S., Zedler, S. E., et al. (1998). Seasonal variability of bio-optical and physical properties in the Arabian Sea: October 1994-October 1995. Deep-Sea Research II, 45, 2001-2025.

Elliott, A. J., \& Savidge, G. (1990). Some features of the upwelling off Oman. Journal of Marine Research, 48, $319-333$.

Fasham, M., Ducklow, H., \& McKelvie, S. (1990). A nitrogen-based model of plankton dynamics in the oceanic mixed layer. Journal of Marine Research, 48, 591-639.

Fieux, M., \& Stommel, H. (1977). Onset of Southwest Monsoon over Arabian Sea from marine reports of surface winds: structure and variability. Monthly Weather Review, 105, 231-236.

Fischer, A. S., Weller, R. A., Rudnick, D. L., Eriksen, C. C., Lee, C. M., Brink, K. H., et al. (2002). Mesoscale eddies, coastal upwelling, and the upper-ocean heat budget in the Arabian Sea. Deep-Sea Research II, 49, 2231-2264.

Flagg, C. N., \& Kim, H. S. (1998). Upper ocean currents in the northern Arabian Sea from shipboard ADCP measurements collected during the 1994-1996 US JGOFS and ONR programs. Deep-Sea Research II, 45, 1917-1959.

Flatau, M., Flatau, P. J., Phoebus, P., \& Niiler, P. P. (1997). The feedback between equatorial convection and local radiative and evaporative processes: the implications for intraseasonal oscillations. Journal of Atmospheric Sciences, 54, $2373-2386$.

Friedrichs, M. A. M. (2001). A data assimilative marine ecosystem model of the central equatorial Pacific: numerical twin experiments. Journal of Marine Research, 59, 859-894.

Friedrichs, M. A. M., Hood, R. R., \& Wiggert, J. D. (2002). The Arabian Sea model testbed: an intercomparison of data assimilative ecosystem models. EOS, Transactions of the American Geophysical Union, 83, 38.

Gallacher, P. C., \& Rochford, P. A. (1995). Numerical simulations of the Arabian Sea tracers as proxies for phytoplankton biomass. Journal of Geophysical Research, 100, 18,565-18,579.

Gardner, W. D., Gundersen, J. S., Richardson, M. J., \& Walsh, I. D. (1999). The role of seasonal and diel changes in mixed-layer depth on carbon and chlorophyll distributions in the Arabian Sea. Deep- Sea Research II, 46, 1833-1858.

Garrison, D. L., Gowing, M. M., \& Hughes, M. P. (1998). Nano- and microplankton in the northern Arabian Sea during the Southwest Monsoon, August-September 1995 - a US-JGOFS study. Deep-Sea Research II, 45, 2269-2299.

Garrison, D. L., Gowing, M. M., Hughes, M. P., Campbell, L., Caron, D. A., Dennett, M. R., et al. (2000). Microbial food web structure in the Arabian Sea: a US JGOFS study. Deep-Sea Research II, 47, 1387-1422.

Gilson, H. C. (1937). The nitrogen cycle. In H. C. Gilson (Ed.). The John Murray Expedition, 1933-34, Scientific Reports (Vol. II, pp. 21-81). London: British Museum (Natural History).

Ginoux, P., Chin, M., Tegen, I., Prospero, J. M., Holben, B., Dubovik, O., et al. (2001). Sources and distributions of dust aerosols simulated with the GOCART model. Journal of Geophysical Research, 106, 20255-20273.

Goes, J. I., Gomes, H. R., Kumar, A., Gouveia, A., Devassy, V. P., Parulekar, A. H., et al. (1992). Satellite and ship studies of phytoplankton along the west coast of India. In B. N. Desai (Ed.), Oceanography of the Indian Ocean (pp. 67-80). New Delhi: Oxford \& IBH Publishing Co.

Gregg, W. W., \& Conkright, M. E. (2002). Decadal changes in global ocean chlorophyll. Geophysical Research Letters, 29 , art. no. 1730 .

Gundersen, J. S., Gardner, W. D., Richardson, M. J., \& Walsh, I. D. (1998). Effects of monsoons on the seasonal and spatial distributions of POC and chlorophyll in the Arabian Sea. Deep-Sea Research II, 45, 2103-2132.

Halpern, D., Freilich, M. H., \& Weller, R. A. (1998). Arabian sea surface winds and ocean transports determined from ERS-1 scatterometer. Journal of Geophysical Research-Oceans, 103, 7799-7805.

Haugen, V. E., Johannessen, O. M., \& Evensen, G. (2002). Mesoscale modeling study of the oceanographic conditions off the southwest coast of India. Proceedings of the Indian Academy of Sciences, Earth and Planetary Sciences, 111, 321-337.

Honjo, S., Dymond, J., Prell, W., \& Ittekkot, V. (1999). Monsoon-controlled export fluxes to the interior of the Arabian Sea. Deep-Sea Research II, 46, 1859-1902.

Hood, R. R., Abbott, M. R., \& Huyer, A. (1991). Phytoplankton and photosynthetic light response in the Coastal Transition Zone off Northern California in June 1987. Journal of Geophysical Research, 96, 14769-14780.

Hood, R. R., Kohler, K. E., McCreary, J. P., \& Smith, S. L. (2003). A four-dimensional validation of a coupled physical-biological model of the Arabian Sea. Deep-Sea Research II, 50, 2917-2945.

Howell, E. A., Doney, S. C., Fine, R. A., \& Olson, D. B. (1997). Geochemical estimates of denitrification in the Arabian Sea and the Bay of Bengal during WOCE. Geophysical Research Letters, 24, 2549-2552.

Idrisi, N., Olascoaga, M. J., Garrafo, Z., Olson, D. B., \& Smith, S. L. (2004). Mechanisms for emergence from diapause of Calanoides carinatus in the Somali Current. Limnology and Oceanography, 49, 1262-1268.

Jamart, B. M., Winter, D. F., Banse, K., Anderson, G. C., \& Lam, R. K. (1977). A theoretical study of phytoplankton growth and nutrient distribution in the Pacific Ocean off the northwestern US coast. Deep-Sea Research I, 24, 753-773.

Kawamiya, M. (2001). Mechanism of offshore nutrient supply in the western Arabian Sea. Journal of Marine Research, 59, 675-696.

Kawamiya, M., \& Oschlies, A. (2003). An eddy-permitting, coupled ecosystem-circulation model of the Arabian Sea: comparison with observations. Journal of Marine Systems, 38, 221-257.

Keen, T. R., Kindle, J. C., \& Young, D. K. (1997). The interaction of southwest monsoon upwelling, advection and primary production in the northwest Arabian Sea. Journal of Marine Systems, 13, 61-82. 
Kim, H. S., Flagg, C. N., \& Howden, S. D. (2001). Northern Arabian sea variability from TOPEX/Poseidon altimetry data: an extension of the US JGOFS/ONR shipboard ADCP study. Deep-Sea Research II, 48, 1069-1096.

Kindle, J. C., Arnone, R., \& Smedstad, O. M. (2002). On the generation of coastal filaments during the Spring Intermonsoon. EOS, Transactions of the American Geophysical Union, 83, 37.

Kovaleva, T. M. (1970). Chlorophyll content in plankton of the Arabian Sea during summer monsoon season. Biologiia Morya (Kiev), 21, 152-165.

Kraus, E. B., \& Turner, J. S. (1967). A one-dimensional model of the seasonal thermocline II. The general theory and its consequences. Tellus, 19, 98-105.

Krey, J. (1973). Primary production and standing stock of phytoplankton and bacteria. In S. A. Gerlach (Ed.). Primary production in the Indian Ocean (Vol. I, pp. 115-126). New York: Springer-Verlag.

Krey, J., \& Babenerd, B. (1976). Phytoplankton production. Atlas of the International Indian Ocean Expedition (p. 70). Kiel: Institut für Meereskunde, Universitat Kiel.

Kumar, S. P., Madhupratap, M., Kumar, M. D., Muraleedharan, P. M., de Souza, S. N., Gauns, M., et al. (2001a). High biological productivity in the central Arabian Sea during the summer monsoon driven by Ekman pumping and lateral advection. Current Science, 81, 1633-1638.

Kumar, S. P., Ramaiah, N., Gauns, M., Sarma, V., Muraleedharan, P. M., Raghukumar, S., et al. (2001b). Physical forcing of biological productivity in the northern Arabian Sea during the Northeast Monsoon. Deep-Sea Research II, 48, $1115-1126$.

Kuzmenko, L. V. (1994). Phytoplankton, primary production and chlorophyll concentration in the Arabian Sea. In H. D. Livingston (Ed.), Biogeochemical processes in the Arabian Sea (pp. 105-110). Sevastopol: Marine Hydrophysical Institute, National Ukrainian Academy of Sciences.

Latasa, M., \& Bidigare, R. R. (1998). A comparison of phytoplankton populations of the Arabian Sea during the Spring Intermonsoon and Southwest Monsoon of 1995 as described by HPLC-analyzed pigments. Deep-Sea Research II, 45, 2133-2170.

Lee, C. M., Jones, B. H., Brink, K. H., \& Fischer, A. S. (2000). The upper-ocean response to monsoonal forcing in the Arabian Sea: seasonal and spatial variability. Deep-Sea Research II, 47, 1177-1226.

Lierheimer, L. J., \& Banse, K. (2002). Seasonal and interannual variability of phytoplankton pigment in the Laccadive (Lakshadweep) Sea as observed by the Coastal Zone Color Scanner. Proceedings of the Indian Academy of Sciences, Earth and Planetary Sciences, 111, 163-185.

Madhupratap, M., Kumar, S. P., Bhattathiri, P. M. A., Kumar, M. D., Raghukumar, S., Nair, K. K. C., et al. (1996). Mechanism of the biological response to winter cooling in the northeastern Arabian Sea. Nature, 384, 549-552.

Manghnani, V., Morrison, J. M., Hopkins, T. S., \& Böhm, E. (1998). Advection of upwelled waters in the form of plumes off Oman during the Southwest Monsoon. Deep-Sea Research II, 45, 2027-2052.

Marra, J., \& Barber, R. T. (2005). Primary productivity in the Arabian Sea: a synthesis of JGOFS data. Progress in Oceanography, this issue, doi:10.1016/j.pocean.2005.03.004.

Marra, J., Dickey, T. D., Ho, C., Kinkade, C. S., Sigurdson, D. E., Weller, R. A., et al. (1998). Variability in primary production as observed from moored sensors in the central Arabian Sea in 1995. Deep-Sea Research II, 45, 2253-2267.

McCarthy, J. J., Garside, C., \& Nevins, J. L. (1999). Nitrogen dynamics during the Arabian Sea Northeast Monsoon. Deep-Sea Research II, 46, 1623-1664.

McCreary, J. P., Kohler, K. E., Hood, R. R., \& Olson, D. B. (1996). A four-component model of biological activity in the Arabian Sea. Progress in Oceanography, 37, 193-240.

McCreary, J. P., Kohler, K. E., Hood, R. R., Smith, S., Kindle, J., Fischer, A. S., et al. (2001). Influences of diurnal and intraseasonal forcing on mixed-layer and biological variability in the central Arabian Sea. Journal of Geophysical Research, 106, 7139-7155.

McCreary, J. P., Kundu, P. K., \& Molinari, R. L. (1993). A numerical investigation of dynamics, thermodynamics and mixed-layer processes in the Indian Ocean. Progress in Oceanography, 31, 181-244.

Measures, C. I., \& Vink, S. (1999). Seasonal variations in the distribution of Fe and Al in the surface waters of the Arabian Sea. DeepSea Research II, 46, 1597-1622.

Moore, J. K., Doney, S. C., Kleypas, J. A., Glover, D. M., \& Fung, I. Y. (2002). An intermediate complexity marine ecosystem model for the global domain. Deep-Sea Research II, 49, 403-462.

Murtugudde, R. G., Signorini, S. R., Christian, J. R., Busalacchi, A. J., McClain, C. R., \& Picaut, J. (1999). Ocean color variability of the tropical Indo-Pacific basin observed by SeaWiFS during 1997-1998. Journal of Geophysical Research, 104, 18,351-18,366.

Naqvi, S. W. A. (1987). Some aspects of the oxygen-deficient conditions and denitrification in the Arabian Sea. Journal of Marine Research, 45, 1049-1072.

Naqvi, S. W. A. (2001). Chemical Oceanography. In E. Desa (Ed.). The Indian Ocean - A perspective (Vol. 1, pp. 159-236). Lidda, Netherlands: A.A. Balkema.

Naqvi, S. W. A., Bange, H., Gibb, S., Goyet, C., Hatton, A., \& Upstill-Goddard, R. (2005). Biogeochemical ocean-atmosphere transfers in the Arabian Sea. Progress in Oceanography, this issue, doi:10.1016/j.pocean.2005.03.005.

Naqvi, S. W. A., Naik, H., \& Narvekar, P. V. (2003). The Arabian Sea. In K. D. Black \& G. B. Shimmield (Eds.), Biogeochemistry of Marine Systems (pp. 157-207). Oxford: Blackwell Publishing, CRC Press. 
O’Brien, T. D., Conkright, M. E., Boyer, T. P., Antonov, J. I., Baranova, O. K., Garcia, H. E., Gelfeld, R., Johnson, D., Locarnini, R. A., Murphy, P. P., Smolyar, I., \& Stephens, C. (2002). World Ocean Database 2001 Vol. 7: Temporal distribution of chlorophyll and plankton data. Technical Report NOAA Atlas NESDIS 48 (219 pp.). Silver Spring, MD: NOAA National Oceanographic Data Center.

Olson, D. B., Hitchcock, G. L., Fine, R. A., \& Warren, B. A. (1993). Maintenance of the low-oxygen layer in the central Arabian Sea. Deep-Sea Research I, 40, 673-685.

Pollehne, F., Klein, B., \& Zeitschel, B. (1993). Low light adaptation and export production in the deep chlorophyll maximum layer in the northern Indian Ocean. Deep-Sea Research I, 40, 737-752.

Premchand, K., Sastry, J. S., \& Murty, C. S. (1986). Watermass structure in the western Indian Ocean II: The spreading and transformation of the Persian Gulf Water. Mausam, 37, 179-186.

Qasim, S. Z. (1978). Distribution of chlorophyll a in the Indian Ocean. Indian Journal of Marine Sciences, 7, $258-262$.

Qasim, S. Z. (1982). Oceanography of the Northern Arabian Sea. Deep-Sea Research I, 29, 1041-1068.

Rhodes, R. C., Hurlburt, H. E., Wallcraft, A. J., Barron, C. N., Martin, P. J., Betzger, E. J., et al. (2002). Navy real-time global modeling systems. Oceanography, 15(1), 29-43.

Rixen, T., Haake, B., Ittekkot, V., Guptha, M. V. S., Nair, R. R., \& Schlussel, P. (1996). Coupling between SW monsoon-related surface and deep ocean processes as discerned from continuous article flux measurements and correlated satellite data. Journal of Geophysical Research, 101, 28,569-28,582.

Rochford, P. A., Kindle, J. C., Gallacher, P. C., \& Weller, R. A. (2000). Sensitivity of the Arabian Sea mixed layer to 1994-1995 operational wind products. Journal of Geophysical Research, 105, 14141-14162.

Rudnick, D. L., Weller, R. A., Eriksen, C. C., Dickey, T. D., Marra, J., \& Langdon, C. (1997). Moored instruments weather Arabian Sea monsoons, yield data. EOS, 78, 117-121.

Ryabchenko, V. A., Gorchakov, V. A., \& Fasham, M. J. R. (1998). Seasonal dynamics and biological productivity in the Arabian Sea euphotic zone as simulated by a three-dimensional ecosystem model. Global Biogeochemical Cycles, 12, 501-530.

Ryther, J. H., Hall, J. R., Pease, A. K., Bakun, A., \& Jones, M. M. (1966). Primary organic production in relation to the chemistry and hydrography of the western Indian Ocean. Limnology and Oceanography, 11, 371-380.

Ryther, J. H., \& Menzel, D. W. (1965). On the production, composition, and distribution of organic matter in the Western Arabian Sea. Deep-Sea Research I, 12, 199-209.

Saji, N. H., Goswami, B. N., Vinayachandran, P. N., \& Yamagata, T. (1999). A dipole mode in the tropical Indian Ocean. Nature, 401, $360-363$.

Sarma, V. (2002). An evaluation of physical and biogeochemical processes regulating perennial suboxic conditions in the water column of the Arabian Sea. Global Biogeochemical Cycles, 16, art. no. 1082.

Sathyendranath, S., Gouveia, A. D., Shetye, S. R., Ravindran, P., \& Platt, T. (1991). Biological control of surface temperature in the Arabian Sea. Nature, 349, 54-56.

Sathyendranath, S., \& Platt, T. (1994). New production and mixed-layer physics. Proceedings of the Indian Academy of Sciences, Earth and Planetary Sciences, 103, 177-188.

Schott, F. A., Dengler, M., \& Schoenefeldt, R. (2002). The shallow overturning circulation of the Indian Ocean. Progress in Oceanography, 53, 57-103.

Schott, F. A., \& McCreary, J. P. (2001). The monsoon circulation of the Indian Ocean. Progress in Oceanography, 51, 1123.

Shalapyonok, A., Olson, R. J., \& Shalapyonok, L. S. (2001). Arabian Sea phytoplankton during Southwest and Northeast monsoons 1995: composition, size structure and biomass from individual cell properties measured by flow cytometry. Deep-Sea Research II, $48,1231-1261$.

Shankar, D., Vinayachandran, P. N., \& Unnikrishnan, A. S. (2002). The monsoon currents in the north Indian Ocean. Progress in Oceanography, 52, 63-120.

Sharada, M. K., \& Yajnik, K. S. (1997). Seasonal variation of chlorophyll and primary productivity in central Arabian Sea: a macrocalibrated upper ocean ecosystem model. Proceedings of the Indian Academy of Sciences-Earth and Planetary Sciences, 106, $33-42$.

Shi, W., Morrison, J. M., Böhm, E., \& Manghnani, V. (2000). The Oman upwelling zone during 1993, 1994 and 1995. Deep-Sea Research II, 47, 1227-1247.

Smith, S. L. (2001). Understanding the Arabian Sea: reflections on the 1994-1996 Arabian Sea Expedition. Deep-Sea Research II, 48, 1385-1402.

Smith, R. L., \& Bottero, J. S. (1977). On upwelling in the Arabian Sea. In M. Angel (Ed.), A voyage of discover (pp. 291-304). New York: Pergamon Press.

Smith, S., Roman, M., Prusova, I., Wishner, K., Gowing, M., Codispoti, L. A., et al. (1998). Seasonal response of zooplankton to monsoonal reversals in the Arabian Sea. Deep-Sea Research II, 45, 2369-2403.

Strom, S. L., Miller, C. B., \& Frost, B. W. (2000). What sets lower limits to phytoplankton stocks in high-nitrate, low-chlorophyll regions of the open ocean? Marine Ecology Progress Series, 193, 19-31. 
Sverdrup, H. U. (1953). On conditions for the vernal blooming of phytoplankton. Journal du Conseil International pour l'Exploration de la Mer, 18, 287-295.

Swallow, J. C. (1984). Some aspects of the physical oceanography of the Indian Ocean. Deep-Sea Research I, 31, 639-650.

Swathi, P. S., Sharada, M. K., \& Yajnik, K. S. (2000). A coupled physical-biological-chemical model for the Indian Ocean. Proceedings of the Indian Academy of Sciences, Earth and Planetary Sciences, 109, 503-537.

Tarran, G. A., Burkill, P. H., Edwards, E. S., \& Woodward, E. M. S. (1999). Phytoplankton community structure in the Arabian Sea during and after the SW monsoon, 1994. Deep-Sea Research II, 46, 655-676.

Tegen, I., \& Fung, I. (1994). Modeling of mineral dust in the atmosphere: sources, transport, and optical thickness. Journal of Geophysical Research, 99, 22897-22914.

Tziperman, E., \& Thacker, W. C. (1989). An optimal-control/adjoint-equations approach to studying the oceanic general circulation. Journal of Physical Oceanography, 19, 1471-1485.

Warren, B. A. (1994). Context of the suboxic layer in the Arabian Sea. Proceedings of the Indian Academy of Sciences, Earth and Planetary Sciences, 103, 203-216.

Weller, R. A., Baumgartner, M. F., Josey, S. A., Fischer, A. S., \& Kindle, J. C. (1998). Atmospheric forcing in the Arabian Sea during 1994-1995: observations and comparisons with climatology and models. Deep-Sea Research II, 45, 1961-1999.

Weller, R. A., Fischer, A. S., Rudnick, D. L., Eriksen, C. C., Dickey, T. D., Marra, J., et al. (2002). Moored observations of upperocean response to the monsoons in the Arabian Sea during 1994-1995. Deep-Sea Research II, 49, 2195-2230.

Wiggert, J. D., Jones, B. H., Dickey, T. D., Weller, R. A., Brink, K. H., Marra, J., et al. (2000). The northeast monsoon's impact on mixing, phytoplankton biomass and nutrient cycling in the Arabian Sea. Deep-Sea Research II, 47, 1353-1385.

Wiggert, J. D., Murtugudde, R. G., \& Christian, J. R. (2004). Biogeochemical variability in the Indian Ocean: Results of a coupled biophysical model. EOS, Transactions of the American Geophysical Union, 84, 52.

Wiggert, J. D., Murtugudde, R. G., \& McClain, C. R. (2002). Processes controlling interannual variations in wintertime (Northeast Monsoon) primary productivity in the central Arabian Sea. Deep-Sea Research II, 49, 2319-2343.

Woodward, E. M. S., Rees, A. P., \& Stephens, J. A. (1999). The influence of the south-west monsoon upon the nutrient biogeochemistry of the Arabian Sea. Deep-Sea Research II, 46, 571-591.

Wooster, W. S. (1984). International studies of the Indian Ocean, 1959-1965. Deep-Sea Research I, 31, 589-597.

Yakovlev, V. N., Trotsenko, B. G., \& Kukharev, N. N. (1994). Brief results of YUGNIRO research in the Arabian Sea and adjacent waters. In H. D. Livingston (Ed.), Biogeochemical processes in the Arabian Sea (pp. 179-183). Sevastopol: Marine Hydrophysical Institute, National Ukrainian Academy of Sciences.

Yakushev, E. V., \& Neretin, L. N. (1997). One-dimensional modeling of nitrogen and sulfur cycles in the euphotic zones of the Black and Arabian Sea. Global Biogeochemical Cycles, 11, 401-414.

Yamagata, T., Behera, S. K., Rao, S. A., Guan, Z. Y., Ashok, K., \& Saji, H. N. (2003). Comments on Dipoles, temperature gradients, and tropical climate anomalies. Bulletin of the American Meteorological Society, 84, 1418-1422.

Yentsch, C. S. (1965). Distribution of chlorophyll and phaeophytin in the ocean. Deep-Sea Research, 12, $653-666$.

Young, D. K., \& Kindle, J. C. (1994). Physical processes affecting availability of dissolved silicate for diatom production in the Arabian Sea. Journal of Geophysical Research, 99, 22619-22632. 